\title{
On the Value of Different Degrees of Centrifugal Force as Geotropic Stimuli.
}

\author{
BY \\ W. E. HILEY, M.A. \\ (Demonstrator in Botany in the University of $O x$ ford $)$.
}

With Plates LVII and LVIII and three Figures in the Text.

HISTORICAL.

THE first plant physiologist to use a centrifugal wheel was Knight 1 (1806). He connected wheels rotating in horizontal and vertical planes with an improvised water-wheel in his garden; and the water served both to drive the wheel and to keep the seedlings moist with incessant spray. Knight worked with seedlings of the 'garden bean', and he found that when they were growing on a wheel with a horizontal axis the radicles all turned outwards and the 'germens' inwards, i. e. towards the axis. But when placed on a wheel which turned about a vertical axis the position taken up by the plant-members was dependent on the rate of rotation of the wheel. When the centrifugal force was about equal to gravity the radicles bent downwards and outwards at an angle of $45^{\circ}$; and as the force was increased the radicles grew nearer and nearer to the horizontal. Knight described his chief discovery as follows: 'I conceive myself to have fully proved that the radicles of germinating seeds are made to descend and their germens to ascend by some external cause; and not by any power inherent in vegetable life: and I see little reason to doubt that gravitation is the principal, if not the only agent employed, in this case, by nature.' He then proceeded to propound an ingenuously mechanistic theory to account for the facts.

But Knight also discovered another very important fact, viz. that gravity as a geotropic stimulus could be replaced by centrifugal force. This discovery is of extreme value because it enables the investigator to substitute a stimulus which can be varied at will for one which is necessarily fixed.

Wigand ('54) carried out a series of experiments with a centrifugal wheel, placing seedlings along a radius at different distances from the centre $\left(3^{\prime \prime}\right.$ to $\left.7^{\prime \prime}\right)$, with the wheel rotating at various rates ( 75 to 2,88 revolutions per min.); he found a marked disparity between the direction assumed by the radicles and the calculated direction of the resultant. There was in one case as great an angle as $38^{\circ}$ between the two directions, but this and

Anna1s of Botany, Vol. XXVII. No. CVIII. October, I9ı3.] 
similar discrepancies were probably due to unhealthy conditions of growth or to unintentional stimulation previous to rotation on the wheel. Wigand succeeded in making radicles grow nearly horizontally on a wheel, with a vertical axis, rotating at high speed. It may be mentioned here that Giltay ('10) undertook to show that radicles did actually take up the position of the resultant of centrifugal force and gravity when growing on a horizontal centrifugal wheel, for Wigand's results had never been experimentally improved upon. As a result of 368 tests, Giltay found them fall $2 \cdot \mathrm{I}^{\circ}$ below the calculated direction of the resultant ; this inaccuracy is slight enough to be accounted for by variations in the speed of rotation.

Sachs ('74) worked on the effect of centrifugal force on secondary roots; he showed that if the radicle of a bean be amputated below the part where secondary roots have been given off, then these secondary roots respond positively to the force.

Elfving ('80) rotated vertically placed radicles on a horizontal wheel so that the radicles bent outwards at an angle to the vertical; and the greater the centrifugal force, the greater was this angle of inclination.

Schwarz ('81) showed that sporangiophores of Mucor are responsive to centrifugal force and bend towards the centre of rotation.

Czapek ('95) was the first to attempt to work out the relation between the speed or magnitude of response and the magnitude of the force. His method was to determine the reaction time (Latenzzeit) of radicles stimulated by centrifugal forces of different magnitudes. He experimented on radicles of Vicia Faba and Lupinus albus (which gave results identical with each other), subjected to forces varying from $0.0005 \mathrm{mg}$. to $3^{8} \mathrm{mg}$. To the former stimulus no reaction was visible after eight hours. Reaction to $0.00 \mathrm{Img}$. took place in six hours and the reaction time gradually diminished to $\frac{3}{4}$ hour for 35 to $38 \mathrm{mg}$.

From this time forward the literature of Geotropism is dominated by the conception of 'presentation time', i.e. the shortest period of exposure to a stimulus that will produce a noticeable after-effect when the object is placed after stimulation either in its normal position or on a horizontal clinostat. This presentation time is a critical time which can be determined experimentally for different plant-members under different experimental conditions, and can be used as a test for sensitiveness of the object worked upon. The conception was first introduced by Czapek ('98), and was further employed by Haberlandt ('03), Fitting ('05), Bach ('07), and many more recent authors. The actual length of this presentation time has tended to diminish markedly, with more exact investigation, even as determined for the same plant-member under similar tonic conditions. Thus, for the hypocotyl of Helianthus annuns: Czapek determined it at $20 \mathrm{~min}$., Fitting at 5 to $6 \mathrm{~min}$., Bach at less than $3 \mathrm{~min}$. Still more recent authors, Polowzow ('09), Tröndle ('13), \&c., have declared that with 
a microscope actual response to the gravitational stimulus can be observed I min. or even $\frac{1}{2} \mathrm{~min}$. after the commencement of stimulation, and that in reality not only presentation time but also reaction time tend to vanish altogether. In that case presentation time comes to mean the least length of exposure to stimulus which will produce a bend visible to the naked eye, and is then of comparatively little value.

Bach ('07) and Pekelharing ('09) have worked out the relationship of presentation time to different angles of displacement and different centrifugal forces, and have shown that it varies inversely as the intensity of the stimulus acting at right angles to the parallelotropic organ.

Others have tried to determine the relation of presentation time to tonic conditions. Thus Bach ('07) and Rütgers ('10) have worked at different temperatures; and the latter author comes to the conclusion that presentation time varies with temperature according to Van't Hoff's law for chemical changes, i. e. for each rise of $10^{\circ} \mathrm{C}$. in the temperature the presentation time is reduced $\frac{1}{2} \frac{0}{6}$ of its length, though this of course can only hold for the limits of temperature within which the seedlings can grow comfortably (i. e. within which other physiological activities are not wholly or partially inhibited). Thus Bach's and Pekelharing's results point to a physical basis for presentation time, whereas Rütgers's point to a chemical basis. The attempt at reconciliation of the two conceptions provides ground for speculation.

Árpád Páal ('11) showed that presentation time varied with artificial changes in the atmospheric pressure.

Buder ('08) tried to accommodate the statolith theory to Bach's figures for presentation time in relation to centrifugal force. His object was to show that when the seedlings of Vicia Faba and Ricinus were turned over, the movable starch-grains in the endodermis of the hypocotyl took just such a time to settle as Bach had worked out to be the presentation time. The presentation time might thus be nothing more or less than the time taken by the starch-grains to settle on the bottom of the statocyte. Also this time would vary inversely as the centrifugal force to which the seedlings were subjected. This theory is very ingenious and would seem to explain the tables obtained by Bach and Pekelharing for the relationship of presentation time to centrifugal forces and angles of displacement. But according to this theory the presentation time must be dependent purely on the specific gravity of the starch-grains and the viscosity of the cell-sap. Thus the relation between presentation time and temperature should be dependent on the relation between viscosity and temperature. But this relationship has been found for water to be approximately as follows :

$$
\text { viscosity coeff. }=\frac{0.01794 \mathrm{I}}{\left(\mathrm{I}+0.023^{\mathrm{I} 20 t)^{1.5423}}\right.}
$$


where $t$ is the temperature in degrees Centigrade. ${ }^{1}$ This means that the vissosity coeff. will be at $80^{\circ} \mathrm{C}$. a third of what it is at $10^{\circ} \mathrm{C}$, a result which is not at all in keeping with Ruitgers's observations of presentation time. Also Heilbronn ('12) has shown that the movable starch-grains do not fall quite freely, but seem to be partially controlled by the streaming protoplasm.

But quite independently of presentation time, another method of investigating the effect of different degrees of stimulation has been employed. This is the method of neutralization of the effects produced by the alternation of opposing stimuli. It was employed independently by Fitting ('05), Newcombe ('05), and Hayes ('05).

The results which Fitting ('05) obtained with his intermittent clinostat are now well known. He was able, through the invention of an extension to Pfeffer's clinostat, to alternate the position of plant-members between two directions at different angles with the vertical; and by this means he was able to compare geotropic effects of various kinds in the two positions. We are here chiefly concerned with one aspect of the work; indeed the fundamental part on which all the other portions of this piece of research may be seen to be dependent.

A plant-member, say a hypocotyl, is made to rest in the position $K$, i. e. horizontal, with the side $A$ uppermost

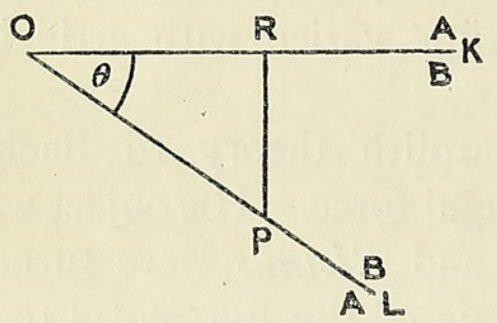
and the side $B$ lowermost. It rests so for a time $t$. Then by a rapid half-rotation of the clinostat axis the hypocotyl is made to assume the position $L$, at an angle $\theta$ below the horizontal and now with the side $B$ uppermost and $A$ lowermost. Here it remains for a period $t^{\prime}$, after which the clinostat axis completes the revolution bringing the hypocotyl back to its former position. The regular alternation of times $t$ and $t^{\prime}$ respectively in the two positions is maintained as long as desired.

When the hypocotyl lies in position $K$ it tends to bend upwards, i. e. towards $A$; when it has taken up the position $L$ it still tends to bend upwards, but now towards $B$. So the tendencies in the two positions are opposed, and a kind of 'tug-of-war' is set up. Which tendency (i. e. to turn towards $A$ or $B$ ) will overcome the other depends on the angle $\theta$ and the relative lengths of the times $t$ and $t^{\prime}$. Fitting found that the two tendencies would exactly neutralize each other (i.e. the hypocotyl would grow straight) when $\frac{t}{t}=\cos \theta,{ }^{2}$ a result which may be expressed geometrically as follows :

1 Thompson and Pointing: Properties of Matter.

${ }^{2}$ Fitting expressed his results in terms of the angle between $O L$ and the vertical. If we call 
If from $P$ (Fig. I), any point on $O L, P R$ is drawn at right angles to $O K$, then $\frac{t}{t^{\prime}}=\frac{O R}{O P}$.

This result may also be expressed in another way. The gravitational stimulus acting at right angles to the hypocotyl in the position $K$ is $m g$, but in the position $L$ it is $m g \cos \theta$. So that if $S$ stands for the stimulating force at right angles to the position $K$ and $S^{\prime}$, that at right angles to the position $L$, we have

$$
\begin{aligned}
\frac{S^{\prime}}{S} & =\cos \theta \\
\therefore \quad \frac{t}{t^{\prime}} & =\frac{S^{\prime}}{S}
\end{aligned}
$$

Thus, for the two bending tendencies to neutralize each other, the times must be inversely proportional to the stimulating forces which act at right angles to the member in the two positions. The result may also be expressed as follows:

$$
S t=S^{\prime} t^{\prime}
$$

i. e. the product of the stimulating force and its time of action is the same in each direction.

Now it seemed desirable to apply this principle to the case of centrifugal forces. This could be done if we could alternate the stimulus of gravity $m g$ acting for a time $t$ in one direction with a centrifugal force $C$ acting for a time $t^{\prime}$ in the opposite direction, each acting at right angles to the plant-member in question. Should we find that when the times were so arranged that the member in question did not bend in either direction, then $m g t=C t^{\prime}$ ? This is the question which the present research sets out to answer.

\section{Note on the Use of the Term 'Centrifugal Force'.}

This term has come into general usage in botanical literature to express the geotropic stimulus obtained on a centrifugal wheel, but as the expression is of doubtful accuracy, we may with advantage carefully consider to what extent the geotropic conditions of stimulus on a centrifugal wheel resemble those under the stimulus of gravity acting on a horizontal plant-member.

The stimulus of gravity may be regarded as follows. If a radicle were free to fall indefinitely without any retarding or accelerating force besides gravity, no geotropic stimulus would act upon it. Just as a man in a lift which, by some accident, fell without restraint, would not be at all conscious of gravity until he reached the limit of the fall, so a plant under similar circumstances would not perceive any gravitational stimulus. The geotropic this $\alpha$, then $\alpha=90^{\circ}-\theta$, therefore $\cos \theta=\sin \alpha$ and the equation may be written $\frac{t}{t^{\prime}}=\sin \alpha$. This has been called the 'sine law'. 
stimulus arises because the plant is held and prevented from falling. This outlook may be expressed in terms of any theory of geotropic perception that may be held; thus, on the basis of the statolith theory, when a root is held horizontally the starch-grains fall to the lower side of each statocyte; but if, when the geotropic member was placed horizontally, the whole was allowed to fall indefinitely, the starch-grains would not reach the lower side of the statocyte, because they would not fall faster than the statocyte as a whole.

Now gravity ' $g$ ' is an acceleration of 32 feet or $98 \mathrm{I} \mathrm{cm}$. per sec. per sec., and this acceleration acts on all parts of a horizontal radicle. The geotropic stimulus is caused by the radicle being prevented from falling. If there were no gravity, the same effect could be produced on the radicle by moving it upwards with an acceleration of 981 cm. per sec. per sec. Movable starch-grains would then fall to the lower side of each statocyte and press upon it just as they do normally under the influence of gravity. Thus the radicles would tend to bend in a direction opposite to that of the acceleration.

Now on the centrifugal wheel a plant-member is always tending to fly off at a tangent, but is prevented from so doing by being held at a constant distance from the centre of rotation. In this way it is subjected to a centripetal acceleration, and it is this which causes the roots to bend centrifugally, i. e. in the direction opposite to that of the acceleration. Thus the so-called 'centrifugal force' might more properly be expressed in terms of this centripetal acceleration.

On the other hand, when we come to consider any sense-organ, the term 'centrifugal force' acquires a new meaning. Thus, in terms of the statolith theory, on the centrifuge the starch-grains move to the outer side and actually do exert a centrifugal force on the outer walls of the statocyte.

In this sense the term 'centrifugal force' may be used in a general way without violence to scientific accuracy. Such an expression as 'a centrifugal force of $10 \mathrm{mg}$. ', when occurring in this paper, may best be interpreted in terms of such a sense-organ. Thus, with the statolith theory, it expresses the force exerted on the outer wall of a statocyte by statoliths whose mass is $m$. Since, by any theory of gravi-perception, sensitiveness to the direction of gravity must presumably be due to the weight of some heavy body or substance, we may speak of centrifugal force (e.g. Io mg.) and not only centrifugal acceleration (e.g. Io g.), realizing that the force is exerted by the heavy body of mass $m$ on the sensitive protoplasm.

To prove the formula $m g t=C t^{\prime}$ it was necessary first to construct a machine which would automatically provide the desired alternation of gravity and centrifugal force acting in opposite directions. 


\section{Description of the Intermittent Centrifuge. ${ }^{1}$}

The centrifuge itself is composed of a $\operatorname{rod} R R$ (Text-fig. I), with a rider $S$ carrying the growing-box $B$. The rod is a hollow brass cylindrical tube, $100 \mathrm{~cm}$. long and $\mathrm{I} .9 \mathrm{~cm}$. in diameter. It is fixed by its middle to the axis $A$. The axis of rotation is vertical and the rod horizontal, so that the

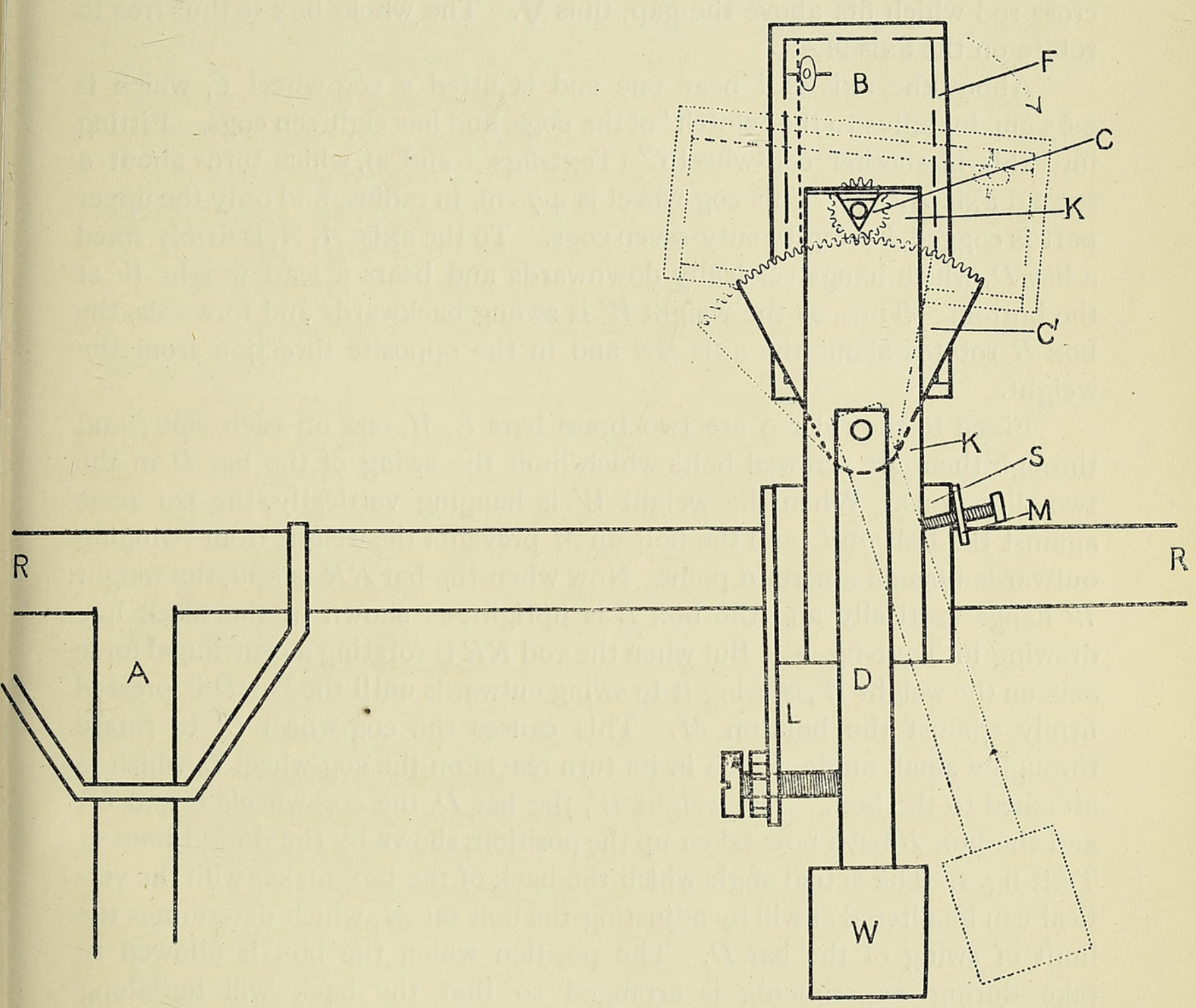

TEXT-FIG. I.

centrifugal force is always exerted in the horizontal plane. The rider $S$ is composed of an oak block $4 \mathrm{~cm}$. broad, $4 \mathrm{~cm}$. high, and $\mathrm{I} 7 \mathrm{~cm}$. long. The rod $R R$ passes through a central hole and the rider is clamped by a butterfly screw as shown in Text-fig. 2, BS. At each end of the oak rider is a brass upright $\left(K K^{\prime}\right.$, Text-figs. I and 2), with a small $\mathbf{V}$ cut out at the top.

The box which contains the seeds is made of cedar wood and is of dimensions $\mathrm{II} \cdot 5 \times 9 \times 4 \mathrm{~cm}$. A glass window is let into the hinged cover

1 The instrument was constructed by Mr. S. W. Bush of the Electrical Laboratory in Oxford. 
(F, Text-fig. I). The back of the box is lined with sheet cork, to which the seeds can be pinned. The box is strengthened by a brass strip $\mathrm{I} \cdot 8 \mathrm{~cm}$. broad, which is bent into the form $\longrightarrow$ clasping the box on the back and at each side. To each of the shorter arms of this strip is attached a steel axis ( $A A$, Text-fig. 2), which fits into the above-mentioned $\mathbf{V} \mathbf{s}$ in the uprights $K K^{\prime}$. The axis is prevented from rising out of the $\mathbf{V}$ by a hinged cross rod which fits above the gap, thus $\overline{\mathbf{V}}$. The whole box is thus free to rotate on the axis $A A$.

About the axis $A A$ near one end is fitted a cog-wheel $C$, which is $0.65 \mathrm{~cm}$. in radius to the 'clutch' of the cogs, and has eighteen cogs. Fitting into this is another cog-wheel $C^{\prime}$ (Text-figs. I and 2), which turns about a second axis $A_{1} A_{1}$. This cog-wheel is $4.7 \mathrm{~cm}$. in radius, and only the upper part is cogged, having twenty-seven cogs. To the axis $A_{1} A_{1}$ is firmly fixed a bar $D$, which hangs vertically downwards and bears a lead weight $W$ at the bottom. Thus, as the weight $W$ is swung backwards and forwards, the box $B$ rotates about the axis $A A$ and in the opposite direction from the weight.

Fixed to the rider $S$ are two brass bars $L, M$, one on each side; and through them are screwed bolts which limit the swing of the bar $D$ in the two directions. When the weight $W$ is hanging vertically, the bar rests against the bolt on $L$, and the bolt on $M$ prevents the weight from swinging outwards beyond a certain point. Now when the bar $R R$ is still, the weight $W$ hangs vertically and the box $B$ is upright, as shown in the black line drawing in Text-fig. I. But when the rod $R R$ is rotating a centrifugal force acts on the weight $W$, causing it to swing outwards until the bar $D$ is pressed firmly against the bolt on $M$. This causes the cog-wheel $C^{\prime}$ to rotate through a small angle, which in its turn reacts on the cog-wheel $C$, which is attached to the box. The weight $W$, the bar $D$, the cog-wheels $C$ and $C^{\prime}$, and the box $B$ have now taken up the positions shown by the dotted lines in Text-fig. I. The actual angle which the back of the box makes with the vertical can be altered at will by adjusting the bolt on $M$, which determines the limit of swing of the bar $D$. The position which the box is allowed to take during experiments is arranged so that the back will lie along the line of the resultant of the centrifugal force acting horizontally and gravity acting vertically.

When, however, the rod $R R$ ceases to rotate and comes to rest, the centrifugal force no longer acts on $W$, so that the bar $D$ sinks back to the black-line position and the box above becomes vertical. Thus the box $B$ has two fixed positions : vertical when the $\operatorname{rod} R R$ is still, and in the line of resultant of the centrifugal force and gravity when the rod is rotating. For the accurate measurement of the angle which the box makes with the vertical in the second position a protractor is fixed to the end of the box $P$ (Text-fig. 2, not shown in Text-fig. I), and by means of the pointer, $p$, the 
angle in question can be read off. Before performing an experiment the centrifugal force is theoretically calculated, and the appropriate angle for the second position is obtained by screwing the bolt in $M$, till the bar $D$ swings to the right extent.

Fig. 4, Pl. LVII, shows the ' wheel' entire. It is propelled by a $\frac{1}{16} \mathrm{~h} . \mathrm{p}$. electric motor which rotates at about 4,000 revolutions per min. By means

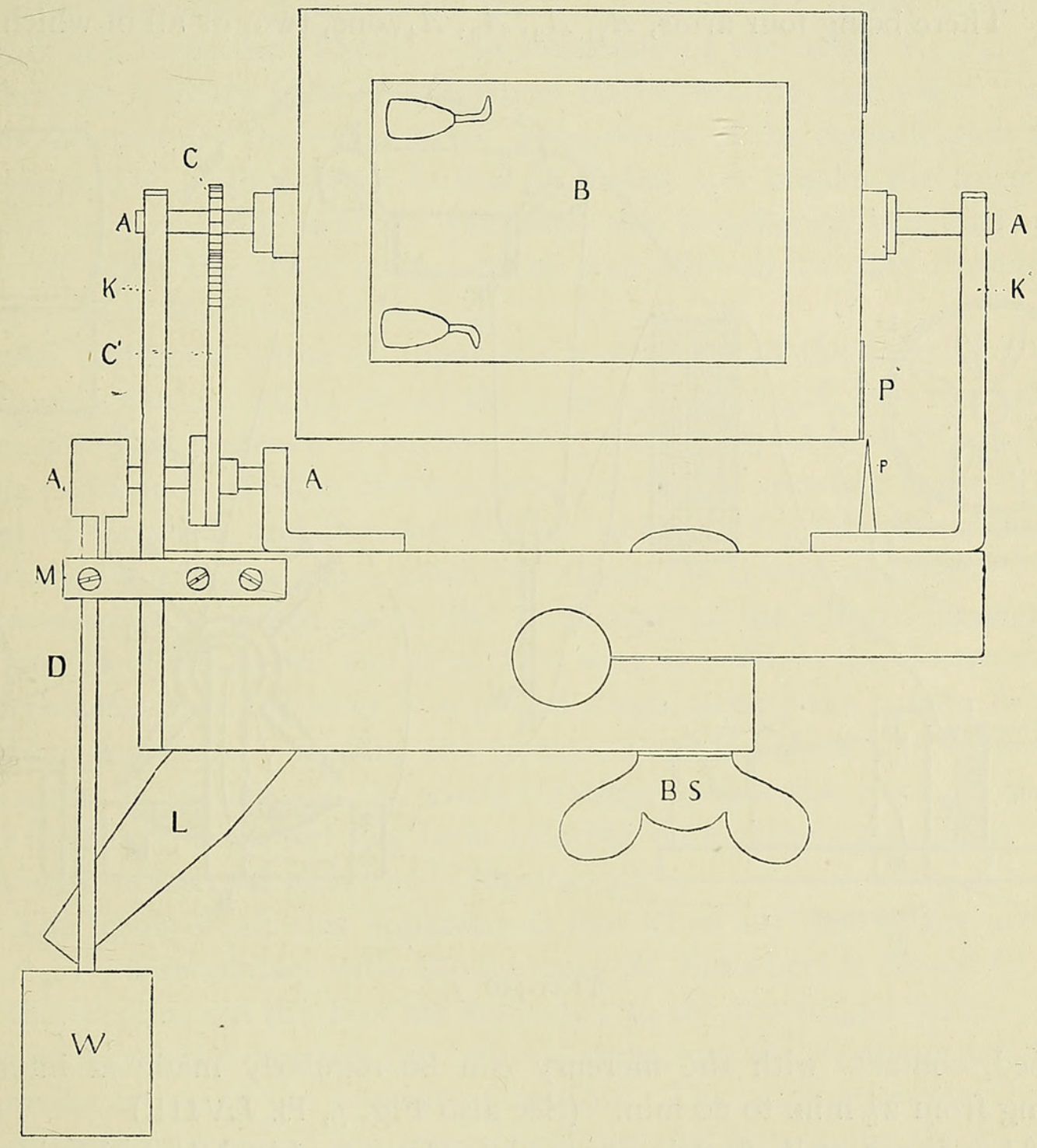

TEXT-Fig. 2.

of two pulleys the rotation of the wheel itself is geared down to about 200 per min. The actual number of rotations made by the 'wheel' is indicated by the rotation recorder, shown below the central pulleys.

The intermittent apparatus is diagrammatically shown in Text-fig. 3 . To the minute axis of a clock $C$ is fixed a pulley round which is wound about three yards of angler's twine. The free end of the twine is passed round one of the pulleys at $D$ and then round the fixed pulleys $p_{1} p_{2}$, eventually round the free pulley $p_{3}$ (to which a weight $W$ is attached), ending up at the 
hook $K$, to which it is fixed. Now as the clock pulley rotates, the twine is gradually set free and the weight $W$ slowly falls, keeping the twine tight, and while this is proceeding the pulley $D$ is made to rotate, and the arms $A_{1}, A_{2}, A_{3}, A_{4}$, which are attached to it, pass successively into the mercury bath $M$. The pulley on the clock rotates once an hour, and the arms $A_{1}$, $A_{2}, A_{3}, A_{4}$ can be made to rotate once in ro min., I5 min., $40 \mathrm{~min}$., or $60 \mathrm{~min}$, according as the twine is passed round the smaller or larger pulleys at $D$. There being four arms, $A_{1}, A_{2}, A_{3}, A_{4}$, one, two, or all of which can

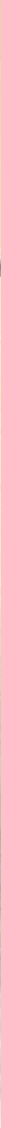

TEXT-FIG. 3 .

be used, contacts with the mercury can be regularly made at intervals varying from $2 \frac{1}{2} \mathrm{~min}$. to $60 \mathrm{~min}$. (See also Fig. 5, Pl. LVIII.)

At $F$ is a 2 -volt electric accumulator, one terminal of which is connected with the mercury bath $M$. To the other terminal is attached a wire which passes round the electro-magnet $E$, and thence is connected with the axis of the pulleys at $D$ and the arms $A_{1}, A_{2}, A_{3}, A_{4}$. Thus, when one of the arms $A_{1}, A_{2}, A_{3}, A_{4}$ is dipping into the mercury bath $M$, the current is made which makes the electro-măgnet operative.

At the point $B$ is loosely hinged a stiff wire $d_{1} d_{2}$, bent downwards at each end. On this wire, in the part $B d_{1}$, is fixed a soft iron plate $I$, just above the magnet. The end $d_{2}$ is weighted so as to make this end heavier. Now when the electro-magnet is not active, the end $d_{2}$, being heavier, 
rests on the support as shown in Text-fig. 3 ; but when one of the arms $A_{1}$, $A_{2}, A_{3}, A_{4}$ touches the mercury $M$, as shown in the dotted line drawing, the electro-magnet $E$ becomes alive and attracts the soft iron $I$, drawing the end $d_{1}$ down so as to touch the mercury in the mercury-bath $m_{1}$. This connects the wire $w_{1}$, which attaches the wire $d_{1} d_{2}$ with the town main, and $w_{2}$, which connects the mercury bath $m_{1}$ with the electric motor $P$, and starts the motor, since the other terminal of the motor is connected with the other terminal of the town main. The electric motor thus starts running and turns the 'wheel'. So when one of the arms $A_{1}, A_{2}, A_{3}, A_{4}$ touches the mercury bath $M$, the wheel starts rotating, and when the arm leaves the mercury the wheel stops. The object of the complication shown in portion III of this figure is that it makes and breaks the town main current very rapidly, and so prevents the lengthened sparking which occurred when the town main current was allowed to pass through the mercury bath $M$ in portion II.

An additional piece of apparatus was added in the form of a clock, which only worked whilst one of the arms $A_{1}, A_{2}, A_{3}, A_{4}$ was touching the mercury. This is shown in portion IV of the figure. A lever $L$ is weighted at the end $l$, and the other end touches an extension attached to the balancewheel of the clock and prevents it from 'going'. On this end of the lever is attached a soft iron plate, which lies above the electro-magnet $E^{\prime}$. This electro-magnet is joined up in the same way as the electro-magnet $E$ in portion III of the figure and is parallel with it. When the electro-magnet $E^{\prime}$ becomes active, the lever $L$ is pulled down, freeing the balance-wheel of the clock and thereby starting the clock. Thus the clock only goes whilst the current is passing and the wheel rotating, so that the clock records the total time that the wheel has been rotating during the experiment.' This clock will be referred to as the 'control clock'.

The result of all this apparatus is that when any one of the arms $A_{1}$, $A_{2}, A_{3}, A_{4}$ is in contact with the mercury $M$, the wheel is caused to rotate and the seedlings in the box are subjected to the centrifugal force. When the arm leaves the mercury the 'wheel' stops, and the seedlings are subject to gravity acting in the opposite direction. The alternation may be kept up as long as required (an experiment usually lasts from six to fifteen hours), and at the end of the time the control clock shows the total period during which the 'wheel' was rotating, and the rotation recorder denotes the number of rotations performed by the 'wheel'. From these data the average rate of rotation of the 'wheel', whilst moving, can be deduced and the centrifugal force worked out. The time during which gravity works alone is determined by subtracting the time recorded by the control clock from the total time of the experiment. 


\section{Working Methods.}

We will take an experiment in which the figures are simple. Suppose we try to find the effect of a stimulus of $9 \mathrm{mg}$. On the rod $R R$ the rider carrying the seedling-box should be placed at about $\mathrm{I} 8 \mathrm{~cm}$. from the centre. The bolt on bar $M$ (Text-fig. I) should be screwed to the point which allows the bar $D$ to swing out so far that the back of the box lies in a plane pointing $6^{\circ}$ below the horizontal $\left(\tan 6^{\circ}=\right.$ about $\left.\frac{1}{9}\right)$, as it will then lie in the line of the resultant of gravity and the centrifugal force. The bands must be arranged round the pulleys so that the wheel may rotate at about 210 . revolutions per minute.

In portion II (Text-fig. 3) we must allow just so much mercury to lie in the bath $M$ that in the revolution of the arms, $A_{1}$ touches the mercury for I min., say, and is free of it for 9 min. The points can be removed from the other arms so that they do not touch the mercury. Thus the 'wheel' will alternately rotate for I min. and be still for 9 min.

When rotating, the middle of the box will be subject to a centrifugal force of $4 \pi^{2} R^{2} r$ dynes or $4 \pi^{2} R^{2} r \frac{1}{9} \frac{1}{81} \mathrm{mg}$. where $r$ is the radius of rotation in centimetres and $R$ the number of revolutions per sec. By our hypothesis $R=\frac{210}{60}=3.5$ and $r=\mathrm{I} 8 . \quad \therefore 4 \pi^{2} R^{2} r=8900$ dynes $=$ about $9 \mathrm{mg}$.

This is at the middle point of the box; but the radius passed through by the outer side of the box is greater than $18 \mathrm{~cm}$., and hence the centrifugal force is greater; and towards the inner side the radius of rotation is less than $18 \mathrm{~cm}$., so that the centrifugal force is less than $9 \mathrm{mg}$. In fact, at the upper (outer) side the centrifugal force will be II mg., and at the lower (inner) side it will be $7 \mathrm{mg}$.

Now, suppose a force of $9 \mathrm{mg}$. acting for I min. exactly counteracts the force of gravity ( $\mathrm{I} \mathrm{mg}$.) acting for $9 \mathrm{~min}$.; then, at the centre of the box the radicles will not bend in either direction, but will grow straight. But in this case a force of I I mg. acting for I min. will more than neutralize a force of I mg. acting for $9 \mathrm{~min}$., so that the radicles growing above the middle will bend outwards. Similarly, below the middle of the box they will bend inwards or downwards. This actually happens in all successful experiments, and Fig. 6, P1. LVIII, shows such a result. There is thus a line of equilibrium across the box, outside which the radicles will bend outwards and inside which they will bend inwards, whilst in this line of equilibrium the radicles remain approximately straight. This will afterwards be referred to as the 'line' or 'point of equilibrium'.

In actual working, owing to variability in the strength of the townmain current, it is impossible exactly to foretell the rate at which the wheel will rotate, and consequently the exact force acting at the centre of the box will not be known till the end of the experiment, when the data supplied by the rotation recorder and the control clock give the required 
value. And it usually happens that the point of equilibrium does not lie exactly in the middle of the box, but either above or below it. In Fig. 6 it lies $2 \mathrm{~cm}$. below the middle of the box, and in taking a reading the centrifugal force at this point has to be worked out.

\section{Two Sources of Error.}

There are two main sources of error in these calculations :

(i) The town-main current is not constant, and this gives rise to irregularity in the rate of rotation of the 'wheel'. Such irregularities are shown in the last column on p. 732 , where variations in rotation are shown from 3.59 revolutions per sec. to 3.75 revolutions per sec., and this within the course of twelve hours. I have found no method of correcting for this error.

(ii) When the motor starts at the commencement of each period of rotation, it does not acquire its full speed for perhaps three or four seconds. Also, when the current ceases to flow, the 'wheel' does not immediately stop. This causes an error in the estimated rate of rotation, worked out from the number of rotations completed and the actual time during which the current has been flowing. This error is most marked when the individual periods of rotation are short, so that the times taken by starting and stopping are longer compared with the time of even running; and also when the bands round the pulleys are slack so that a considerable amount of slipping is allowed. When the individual periods of rotation are long, and the bands are tight, no correction need be made for this error.

I have been able to compensate for this error, to some extent at any rate, in the following way.

To take an example: the current flows for 30 seconds, but owing to the momentum acquired the 'wheel' rotates for 35 seconds, i.e. for 5 seconds after the current has ceased to flow. In this total time $(35 \mathrm{sec}$.) the 'wheel' makes I07 revolutions. Now, working out the value of the centrifugal force from the data of the control clock and the rotation recorder, we have

$$
R=\frac{107}{30}=3.57 \therefore R^{2}=\mathrm{I} 2 \cdot 74 \text { and } C=\frac{4 \pi^{2} R^{2} r}{98 \mathrm{I}}=22.9 \mathrm{mg} .
$$

since in this experiment the radius of rotation was $45 \mathrm{~cm}$. A period was then carefully watched and the number of revolutions in each five seconds was recorded with the following result:

\begin{tabular}{|c|c|c|c|c|c|c|c|c|}
\hline Ist period of $5 \mathrm{sec}$. & & olutions & $R^{2}=$ & $3 \cdot 2$ & $C=$ & $\cdot$ & $C t=C \times 5=$ & $\begin{array}{l}28 \cdot 5 \\
8 I \cdot 0\end{array}$ \\
\hline " & I5 & " & & 9 & & $16 \cdot 2$ & & $\begin{array}{r}81 \cdot 0 \\
102 \cdot 5\end{array}$ \\
\hline " & I 7 & " & $"$ & I I 5 & , & $20 \cdot 7$ & , & 103.5 \\
\hline , & I 7 & ", & , & I I $\cdot 5$ & , & $20 \cdot 7$ & ", & 103.5 \\
\hline , & I 7 & ", & , & I I $\cdot 5$ & , & $20 \cdot 7$ & , & 103.5 \\
\hline ", & I 7 & ", & , & I I $\cdot 5$ & , & $20 \cdot 7$ & ," & 103.5 \\
\hline , & I 2 & ", & , & $5 \cdot 7$ & ", & 10.2 & ," & $5^{I \cdot O}$ \\
\hline
\end{tabular}

Total in $C t$ units $=574.5$

(The $C t$ unit represents a force of I $\mathrm{mg}$. acting for one second). 
But as determined by the control clock and rotation recorder the stimulation was $22.9 \mathrm{mg}$. acting for thirty seconds, which represents $687 \mathrm{Ct}$ units.

I now assume that the stimulating power as reckoned by the method of summation of the stimulating force for each five seconds is more accurate than that reckoned from the total number of revolutions and the time the current was flowing. In this case a more accurate value for the stimulating force is obtained by multiplying the recorded centrifugal force by $\frac{574 \cdot 5}{687}$ or 0.84 .

This correction I call the Mechanical error correction, and this will be quoted by saying M.E.C. $=0.84$.

The example here taken is one in which the mechanical error correction makes a very great difference. This is due to the fact that in this experiment (i) the bands were very slack so that a considerable amount of slipping was possible, which made the 'wheel' both slow in getting up speed and slow in stopping, (ii) the period of running was short, so that the starting and stopping took up a greater amount of time in proportion to the time of normal running; and (iii) the rider was far out on the $\operatorname{rod} R R$ so that the wheel acquired a great momentum.

\section{Specimen Experiment.}

July 29, I9I2. Helianthus annuus radicles.

Total period $(t+T)=$ I I min. where $t$ is the length of one period still, and $T$ the length of one period of rotation.

Temp. $=20^{\circ} \mathrm{C}$.

$\theta=$ angle made with vertical by back of box when rotating $=96^{\circ}$.

Distance of middle of box from centre of rotation $=20 \mathrm{~cm}$.

$\begin{array}{ccc}\text { Time. Control Time } & \text { Rotation Rotations } \\ & \text { Clock. rotating. } & \text { recorder. per sec. }\end{array}$

h. m. s. h.m. s. m. s.

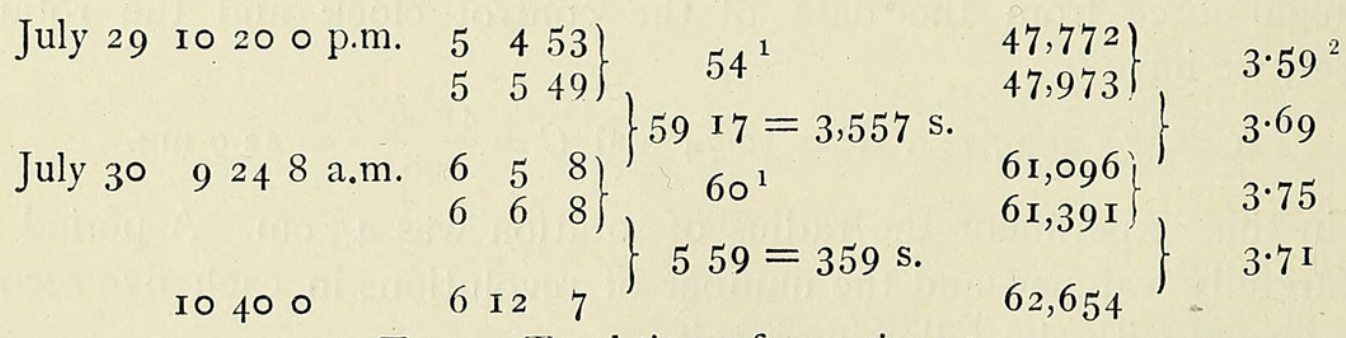

From the above $\frac{t+T}{T}=\frac{\text { Total time of experiment }}{\text { Time recorded by control clock }}$

$\therefore \frac{t}{T}=10.0$

$$
=\frac{22^{\mathrm{h}} 40^{\mathrm{m}}-10^{\mathrm{h}} 20^{\mathrm{m}}}{6^{\mathrm{h}} 12^{\mathrm{m}} 7^{\mathrm{s}}-5^{\mathrm{h}} 4^{\mathrm{m}} 5^{8 \mathrm{~s}}}=\frac{44,400^{\mathrm{s}}}{4,034^{\mathrm{s}}}=1 \mathrm{I} \cdot 0 \text {. }
$$

1 This is the actual length of a period of rotation. It could not be kept quite constant.

2 This figure is obtained by dividing the number of revolutions by the number of seconds during which the 'wheel' was revolving,

$$
\text { i.e. } \text { it }=\frac{47,973-47,77^{2}}{54}=3.59 \text {. }
$$


$R=$ average number of rotations per sec. whilst running

$\therefore R^{2}=\mathrm{I} 3 \cdot 2$.

$$
=\frac{62,654-47,772}{4,034}=3.69 \text {. }
$$

Now in this experiment the point of equilibrium was $\mathrm{I} \mathrm{cm}$. below the middle of the box, and at this point the radius of rotation $=19 \mathrm{~cm}$., i. e. $r=\mathbf{I} 9$.

Cent. force $=\pi^{2} R^{2} r=39 \cdot 5 \times 13.2 \times 19$

$$
\begin{aligned}
& =10,222 \text { dynes } \\
& =\frac{10,222}{981} \mathrm{mg} . \\
& =10.4^{2} \mathrm{mg} .
\end{aligned}
$$

But since gravity was also working the whole time we should take the value of the resultant of gravity and the centrifugal force in the direction $6^{\circ}$ below the horizontal.

This $=C=\left(10.42 \cos 6^{\circ}+\mathbf{I} \sin 6^{\circ}\right) \mathrm{mg}$.

$$
\begin{aligned}
& =(\mathrm{r} 0.42 \times 0.9945+0.1045) \mathrm{mg} . \\
& =\mathrm{I}_{0} .4^{6} \mathrm{mg} .{ }^{1}
\end{aligned}
$$

In this experiment the value of the mechanical error correction, i. e. M.E.C. $=0.93$.

$\therefore C$ (corrected) $=10.46 \times 0.93=9.7 \mathrm{mg} . \quad \therefore \frac{C}{m g}=9.7$, but $\frac{t}{T}=\mathbf{1}$.

$\therefore \frac{C . T}{m g . t}=0.97$, which is an approximation to $\mathbf{I}$.

\section{EXPERIMENTS.}

Helianthus annuns. The 'seeds' of Helianthus were soaked in water for twenty-four hours in a dish, which in winter was placed on the hot-water pipes. They were then sown upright in damp sand and kept at a temperature of about $20^{\circ} \mathrm{C}$. They were ready for experimenting from forty-eight to seventytwo hours after the commencement of soaking. In general the radicles were 2 to Io $\mathrm{mm}$. long at the beginning of an experiment. In all about I 35 experiments have been carried out on the radicles of Helianthus anmuns; but of these the first fifty have been disregarded, as in the light of later experience it was seen that sufficient precautions had not been taken in these earlier experiments to avoid errors. They served the purpose of providing experience in the use of the centrifugal machine, but will not be employed in deducing results. In many others the line of equilibrium did not fall within the limits of the box, so that the radicles either bent all upwards or all downwards. From these it can only be shown that with the times taken $(t$ and $T)$ the centrifugal force necessary just to neutralize gravity is either less or greater than the calculable amount. If it had been possible to predict at the beginning of the experiment the centrifugal force that would be obtained sufficiently closely, failures arising from this source

1 When the centrifugal force is high this correction makes very little difference and can be neglected. 
could have been prevented. Other experiments failed owing to the accumulator running down or other parts of the instrument going wrong.

The following list of experiments includes all those in which none of the above-mentioned causes of failure occurred. The experiments are arranged in order of the centrifugal forces used, not in the order in which they were performed.

${ }^{1}$ Experiment I. Sept. I7, I9I 2.9 .27 a.m. to 3 p.m.

Temp. $=20^{\circ} \mathrm{C}$.

Radius of rotation at middle of box $=6.5 \mathrm{~cm}$.

$\theta=\mathrm{I} \circ 5^{\circ}$.

Total period $(t+T)=\mathbf{I} \mathbf{I}$.

$\frac{t}{T^{2}}=3 \cdot 3 \mathrm{I}$.

$R=3.92$.

Point of equilibrium is $\mathbf{I} \cdot 5 \mathrm{~cm}$. below middle of box.

$\therefore r=$ Radius of rotation here $=5 \mathrm{~cm}$.

Cent. force here $=3.09 \mathrm{mg}$.

$\mathrm{C}=$ resultant of centrifugal force and gravity $=3.42 \mathrm{mg}$.

Thus $\frac{t}{T}=3 \cdot 3 \mathrm{I}, \frac{C}{m g}=3.24$.

$\therefore \frac{C T}{m g . t}=\mathbf{1} \cdot 02$.

Experiment 2. Sept. I 5, I 9 I 2 . IO. I 5 a.m. to 4.5 p.m.

Temp. $=20^{\circ} \mathrm{C}$.

Radius of rotation at middle of box $=7 \mathrm{~cm}$.

$\theta=105^{\circ}$.

Total period $(t+T)=7 \mathrm{~m} \cdot 30 \mathrm{~s}$.

$\frac{t}{T}=3 \cdot 17$.

$R=4.045$.

Point of equilibrium is $2.0 \mathrm{~cm}$. below middle.

$\therefore r=5 \mathrm{~cm}$.

Cent. force $=3 \cdot 3 \circ \mathrm{mg}$.

$C=3.45 \mathrm{mg}$.

Thus $\frac{t}{T}=3 \cdot \mathrm{I} \eta, \frac{C}{m g}=3 \cdot 45$.

$\therefore \frac{C T}{m g \cdot t}=\mathbf{1} \cdot 09$.

Experiment 3. Sept. I5, igi 2.4 4. 5 p.m. to io.2 p.m.

Temp. $=20^{\circ} \mathrm{C}$.

Radius of rotation at middle of box $=7 \mathrm{~cm}$.

$\theta=105^{\circ}$.

1 For the meaning of symbols see 'Specimen Experiment', p. $73^{2}$. 
Total period $(t+T)=7 \mathrm{~m} .50 \mathrm{~s}$.

$\frac{t}{T}=4 \cdot 5$.

$R=4.086$.

Point of equilibrium is $0.5 \mathrm{~cm}$. below middle of box.

$\therefore r=6.5 \mathrm{~cm}$.

Cent. force $=4 \cdot 36 \mathrm{mg}$.

$C=4.5 \mathrm{I} \mathrm{mg}$.

Thus $\frac{t}{T}=4 \cdot 5, \frac{C}{m g}=4 \cdot 5 \mathrm{r}$.

$\therefore \frac{C T}{m g \cdot t}=\mathbf{r} \cdot 00$.

Experiment 4. Sept. I 5, I 9 I 2, I0.I 4 p.m., to Sept. I 6, 9.25 a.m.

Temp. $=20^{\circ} \mathrm{C}$.

Radius of rotation at middle of box $=7 \mathrm{~cm}$.

$\theta=105^{\circ}$.

Total period $(t+T)=7 \mathrm{~m} \cdot 30 \mathrm{~s}$.

$\frac{t}{T}=5 \cdot 65$.

$R=4 \cdot 37$.

Point of equilibrium is at middle of box.

$\therefore r=7 \mathrm{~cm}$.

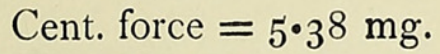

$C=5.45 \mathrm{mg}$.

Thus $\frac{t}{T}=5.65, \frac{C}{m g}=5.45$.

$\therefore \frac{C T}{m g \cdot t}=0.96$.

Experiment 5. Sept. i 9, i 9 i 2. $9.5^{\circ}$ a.m. to 5.25 p.m.

Temp. $=20^{\circ} \mathrm{C}$.

Radius of rotation at middle of box $=10 \mathrm{~cm}$.

$\theta=105^{\circ}$.

Total period $(t+T)=7 \mathrm{~m} .30 \mathrm{~s}$.

$\frac{t}{T}=5 \cdot 30$.

$R=3 \cdot 85$.

Point of equilibrium is $\mathbf{I} \mathrm{cm}$. below middle of box.

$\therefore r=9 \mathrm{~cm}$.

Cent. force $=5 \cdot 40 \mathrm{mg}$.

$C=5.47 \mathrm{mg}$.

Thus $\frac{t}{T}=5 \cdot 3 \circ, \frac{C}{m g}=5 \cdot 47$.

$\therefore \frac{C T}{m g \cdot t}=\mathbf{1} \cdot 03$. 
Experiment 6. May 9, i 9 I 2.9 .25 a.m. to 8.30 p.m.

Temp. $=20^{\circ} \mathrm{C}$.

Radius of rotation at middle of box $=I_{5} \mathrm{~cm}$.

$\theta=\mathrm{I} 00^{\circ}$.

Total period $(t+T)=$ I I $\mathrm{m}$.

$\frac{t}{T}=7 \cdot 97$.

$R=3 \cdot 6$ I.

Point of equilibrium is I $\mathrm{cm}$. below middle of box.

$\therefore r=\mathrm{I} 4 \mathrm{~cm}$.

Cent. force $=7 \cdot 34 \mathrm{mg}$.

$C=7 \cdot 40 \mathrm{mg}$.

Thus $\frac{t}{T}=7 \cdot 97, \frac{C}{m g}=7 \cdot 40$.

$\therefore \frac{C T}{m g . t}=0.93$.

Experiment 7. June 2I, igr 2 . I0.20 a.m. to 6.40 p.m.

Temp. $=2 \mathrm{I}^{\circ} \mathrm{C}$.

Radius of rotation at middle of box $=\mathbf{I} 5 \mathrm{~cm}$.

$\theta=\mathrm{I} 00^{\circ}$.

Total period $(t+T)=\mathbf{I} \mathbf{I} \mathrm{m}$.

$\frac{t}{T}=7 \cdot 94$.

$R=3.82$.

Point of equilibrium is $\mathbf{I} \cdot 5 \mathrm{~cm}$. below middle of box.

$\therefore r=\mathrm{I} 3.5$.

Cent. force $=7.93 \mathrm{mg}$.

$C=7.98 \mathrm{mg}$.

And M.E.C. $=\mathrm{I} \cdot 00$.

Thus $\frac{t}{T}=7.94, \frac{C}{m g}=7.98$.

$\therefore \frac{C T}{m g \cdot t}=\mathbf{I} \cdot 0 \mathrm{I}$.

Experiment 8. July 29, i 9 I 2, I0.20 p.m., to July 30, I0.40 a.m.

Temp. $=20^{\circ} \mathrm{C}$.

Radius of rotation at middle of box $=20 \mathrm{~cm}$.

$\theta=96^{\circ}$.

Total period $(t+T)=\mathbf{I} \mathrm{m}$.

$\frac{t}{T}=\mathrm{I} 0.0$.

$R=3.69$.

Point of equilibrium is I $\mathrm{cm}$. below middle of box.

$\therefore r=19 \mathrm{~cm}$.

Cent. force $=10.42 \mathrm{mg}$.

$C=10.46 \mathrm{mg}$. 
And $M . E . C .=0.93$.

$\therefore C$ (corrected) $=9 \cdot 7 \mathrm{mg}$.

Thus $\frac{t}{T}=$ I $0.0, \frac{C}{m g}=9 \cdot 7$.

$\therefore \frac{C T}{m g \cdot t}=0.97$.

Experiment 9. May 4, I 9 I 2. I I.50 a.m. to io.20 p.m.

Temp. $=20^{\circ} \mathrm{C}$.

Radius of rotation at middle of box $=20 \mathrm{~cm}$.

$\theta=96^{\circ}$.

Total period $(t+T)=\mathbf{I} \mathbf{I}$.

$\frac{t}{T}=\mathrm{I} 0.5$.

$R=3 \cdot 78$.

Point of equilibrium is $2 \mathrm{~cm}$. below middle of box.

$\therefore r=\mathrm{I} 8 \mathrm{~cm}$.

Cent. force $=10.35 \mathrm{mg}$.

$C=10.39 \mathrm{mg}$.

Thus $\frac{t}{T}=10.5, \frac{C}{m g}=10.39$.

$\therefore \frac{C T}{m g \cdot t}=0.99$

Experiment io. Dec. I8, igi i. IO.I 9 a.m. to 9.40 p.m.

Radius of rotation at middle of box $=30 \mathrm{~cm}$.

$\theta=94^{\circ}$.

Total period $(t+T)=5 \mathrm{~m} .30 \mathrm{s.}^{1}$

$\frac{t}{T}=\mathrm{I} \mathbf{\mathrm { I }} \cdot 3^{\circ}$.

$R=3.03$.

Point of equilibrium is $\mathbf{I} \cdot 5 \mathrm{~cm}$. below middle of box.

$\therefore r=28.5 \mathrm{~cm}$.

Cent. force $=10.5^{2} \mathrm{mg} .=C .^{2}$

Thus $\frac{t}{T}=\mathrm{I} \mathrm{I} \cdot 30, \frac{C}{m g}=10 \cdot 5^{2}$.

$\therefore \frac{C T}{m g \cdot t}=0.93$.

Experiment I I. Dec. i 7, i 9 I I. I i.35 a.m. to i i.30 p.m.

Temp. $=19^{\circ} \mathrm{C}$.

Radius of rotation at middle of box $=30 \mathrm{~cm}$.

$\theta=94^{\circ}$.

${ }^{1}$ In this experiment the times were arranged differently. The wheel rotated for $26 \mathrm{~s}$., was still for $2 \mathrm{~m}$. I $7 \mathrm{~s}$. ; rotated for $27 \mathrm{~s}$., and still for $8 \mathrm{~m}$. It then started rotating again for 26 secs.

2 When $\theta$ is less than $96^{\circ}$, the resultant of the centrifugal force and gravity is so near the former that it may be taken as equal to it. 
Total period $(t+T)=5 \mathrm{~m} .30 \mathrm{~s}$.

$\frac{t}{T}=\mathrm{I} \cdot 6$.

$R=3 \cdot 0$.

Point of equilibrium is $\mathbf{I} \mathrm{cm}$. below the middle of box.

$\therefore r=29 \mathrm{~cm}$.

Here $C=\mathrm{II} \cdot 4 \mathrm{mg}$.

Thus $\frac{t}{T}=\mathrm{I} \cdot 6, \frac{C}{m g}=\mathrm{I} \mathrm{I} \cdot 4$.

$\therefore \frac{C T}{m g \cdot t}=0.98$.

Experiment i 2. Dec. i 9, I 9 I I. 8.27 a.m. to 3.45 p.m.

Temp. $=19^{\circ} \mathrm{C}$.

Radius of rotation at middle of box $=30 \mathrm{~cm}$.

$\theta=94^{\circ}$.

Total period $(t+T)=7$ m. $45 \mathrm{s.}^{1}$

$\frac{t}{T}=\mathbf{r} 3.8$.

$R=3 \cdot 37$.

Point of equilibrium is $\mathrm{I} \mathrm{cm}$. below middle of box.

$\therefore r=29 \mathrm{~cm}$.

$C=\mathrm{I} 3.2 \mathrm{mg}$.

Thus $\frac{t}{T}=\mathrm{I} 3 \cdot 8, \frac{C}{m g}=\mathbf{1} 3 \cdot 2$.

$\therefore \frac{C T}{m g \cdot t}=0.96$.

Experiment i 3. April 28, i 9 I 2. I0.23 a.m. to i I p.m.

Temp. $=20^{\circ} \mathrm{C}$.

Radius of rotation at middle of box $=27 \mathrm{~cm}$.

$\theta=94^{\circ}$.

Total period $(t+T)=$ I I $\mathrm{m}$.

$\frac{t}{T}=\mathrm{r} 6 \cdot 5$.

$R=3 \cdot 74$.

Point of equilibrium is at middle of box.

$\therefore r=27 \mathrm{~cm}$.

$C=15.2 \mathrm{mg}$.

Thus $\frac{t}{T}=\mathrm{I} 6 \cdot 5, \frac{C}{m g}=\mathrm{I} 5 \cdot 2$.

$\therefore \frac{C T}{m g \cdot t}=0.92$.

137 sec. rotation, 3 min. 2 I sec. rest; 26 sec. rotation, I I min. 7 sec. rest, and repeat. 
Experiment I 4. Jan. 20, I 9 I 2 . Io.40 a.m. to 9. Io p.m.

Temp. $=19^{\circ} \mathrm{C}$.

Radius of rotation at middle of box $=30 \mathrm{~cm}$.

$\theta=94^{\circ}$.

Total period $(t+T)=15 \mathrm{~m} .30 \mathrm{~s}$.

$\frac{t}{T}=\mathrm{i} 6 \cdot 3$.

$R=3.88$.

Point of equilibrium is $3 \mathrm{~cm}$. below middle of box.

$\therefore r=27 \mathrm{~cm}$.

$C=\mathrm{I} 6.4 \mathrm{mg}$.

Thus $\frac{t}{T}=\mathrm{I} 6 \cdot 3, \frac{C}{m g}=\mathrm{I} 6 \cdot 4$.

$\therefore \frac{C T}{m g \cdot t}=\mathbf{I} \cdot$ or.

Experiment I 5. Jan. I8, i 9 I 2. I0.20 a.m. to 5.10 p.m.

Temp. $=20^{\circ} \mathrm{C}$.

Radius of rotation at middle of box $=30 \mathrm{~cm}$.

$\theta=94^{\circ}$.

Total period $(t+T)=$ I I $\mathrm{m}$.

$\frac{t}{T}=\mathbf{1} 7 \cdot 7$.

$R=3.83$.

Point of equilibrium is at middle of box.

$\therefore r=30 \mathrm{~cm}$.

$C=\mathrm{I} 7.7 \mathrm{mg}$.

Thus $\frac{t}{T}=\mathrm{I} 7 \cdot 7, \frac{C}{m g}=17 \cdot 7$.

$\therefore \frac{C T}{m g \cdot t}=\mathrm{I} \cdot 00$.

Experiment i6. March 23, i9i 2. I i.io a.m. to io.20 p.m.

Radius to rotation at middle of box $=45 \mathrm{~cm}$.

$\theta=92^{\circ}$.

Total period $(t+T)=$ I I $\mathrm{m}$.

$\frac{t}{T}=\mathbf{1} 8 \cdot 2$.

$R=3 \cdot 47$.

Point of equilibrium is at middle of box.

$\therefore r=45 \mathrm{~cm}$.

$C=2 \mathrm{I} \cdot 8 \mathrm{mg}$.

M.E.C. $=0.85 .^{1}$

$\therefore C$ (corrected) $=\mathbf{1} 8.5 \mathrm{mg}$.

1 The mechanical error was great owing to the bands having become very loose. 


$$
\begin{aligned}
& \text { Thus } \frac{t}{T}=\mathbf{1} 8 \cdot 2, \frac{C}{m g}=\mathrm{I} 8.5 . \\
& \therefore \frac{C T}{m g \cdot t}=\mathrm{I} \cdot 02 .
\end{aligned}
$$

Experiment I7. March 26, 19 I 2. IO. Io a.m. to 9.I 5 p.m.

Temp. $20^{\circ} \mathrm{C}$.

Radius of rotation at middle of box $=45 \mathrm{~cm}$.

$\theta=92^{\circ}$.

Total period $(t+T)=\mathrm{I} \mathrm{I} \mathrm{m}$.

$\frac{t}{T}=\mathrm{I} 9 \cdot 0$.

$R=3 \cdot 5^{6}$.

Point of equilibrium is $2.5 \mathrm{~cm}$. below middle of box.

$\therefore r=42.5 \mathrm{~cm}$.

$C=2 \mathrm{I} \cdot 4 \mathrm{mg}$.

But M.E.C. $=0.8 \%$.

$\therefore C$ (corrected) $=\mathbf{1} 8.6 \mathrm{mg}$.

Thus $\frac{t}{T}=\mathrm{I} 9 \cdot 0, \frac{C}{m g}=\mathrm{I} 8.6$.

$\therefore \frac{C T}{m g . t}=0.98$.

Experiment i 8. March 22, i 9 I 2 . i i.30 a.m. to 9.20 p.m.

Temp. $20^{\circ} \mathrm{C}$.

Radius of rotation at middle of box $=45 \mathrm{~cm}$.

$\theta=92^{\circ}$.

Total period $(t+T)=$ I I $\mathrm{m}$.

$\frac{t}{T}=20 \cdot 85$.

$R=3.66$.

Point of equilibrium is $0.5 \mathrm{~cm}$. above middle of box (not very clear).

$\therefore r=45.5 \mathrm{~cm}$.

$C=24 \cdot 6$.

But M.E.C. $=0.85$.

$\therefore C$ (corrected) $=20.9 \mathrm{mg}$.

Thus $\frac{t}{T}=20.85, \frac{C}{m g}=20.9$.

$\therefore \frac{C T}{m g \cdot t}=\mathbf{I} \cdot 00$.

The above results are summed up in the following table: 


\section{TABLE I.}

Helianthus annuus radicles. Temp. about $20^{\circ} \mathrm{C}$.

\begin{tabular}{|c|c|c|c|c|c|}
\hline No. of & $\frac{C}{a}$ & $\frac{t}{T}$ & $(t+$ & & $C T$ \\
\hline & & & m. & S. & \\
\hline I & 3.24 & $3 \cdot 3 \mathrm{I}$ & I I & $\circ$ & \\
\hline 2 & $3 \cdot 45$ & $3 \cdot$ I 7 & 7 & 30 & I. \\
\hline 3 & $4 \cdot 5^{\mathrm{I}}$ & 4.5 & 7 & 30 & $\mathbf{I}$ \\
\hline 4 & $5 \cdot 45$ & $5 \cdot 65$ & 7 & $3^{\circ}$ & \\
\hline 5 & $5 \cdot 47$ & $5 \cdot 30$ & 7 & $3^{\circ}$ & $I \cdot C$ \\
\hline 6 & $7 \cdot 4$ & $7 \cdot 97$ & I I & 0 & 0 \\
\hline 7 & 7.98 & $7 \cdot 94$ & I I & o & I. \\
\hline 8 & $9 \cdot 7$ & 10.0 & I I & 0 & \\
\hline 9 & 10.39 & 10.5 & I I & o & \\
\hline 10 & $10.5^{2}$ & I I $\cdot 30$ & 5 & 30 & \\
\hline II & II $\cdot 4$ & I I $\cdot 6$ & 5 & 30 & \\
\hline 12 & $13 \cdot 2$ & 13.8 & 7 & 45 & \\
\hline I3 & I 5.2 & 16.5 & I I & 0 & \\
\hline I 4 & 16.4 & $16 \cdot 3$ & I 5 & 30 & \\
\hline 15 & $17 \cdot 7$ & $17 \cdot 7$ & I I & 。 & \\
\hline 16 & $18 . \dot{5}$ & 18.2 & I I & ० & \\
\hline I 7 & 18.6 & 19.0 & I I & o & \\
\hline 18 & 20.9 & 20.85 & I I & o & \\
\hline
\end{tabular}

Results with short total periods.

Average value of $\frac{C T}{m g . t}=0.99$.

The above results show that to a very near approximation $\frac{C T}{m g \cdot t}=\mathrm{I}$ or $C T=m g . t$., i. e. the stimulating force multiplied by the time of action must be the same in each direction if a radicle is to remain straight under the influence of two opposing alternating stimuli.

But it should be noted that the total period $(t+T)$ was never allowed to exceed $15 \mathrm{~min}$. $30 \mathrm{sec}$. A large number of experiments, however, were performed with longer periods, but the results were quite out of keeping with those quoted above. It was usually impossible to trace a definite line of equilibrium across the box, so that any results that are given below are not very exact. And in many of the experiments the radicles all bent downwards, showing that the line of equilibrium is outside the box and further from the centre of rotation; so that for equilibrium $C$ must be greater than that at the upper edge of the box.

The following experiments are quoted to show that the equation $C T=m g . t$ does not hold if the total periods are long. In general the greater the centrifugal force and the longer the total period, the higher is the value of $\frac{C T}{m g \cdot t}$. 
Experiments with Helianthus annuus radicles, using total periods of more than twenty minutes.

Experiment I9. May i I, I9II. I I a.m. to 8 p.m.

Temp. $=25^{\circ} \mathrm{C}$.

Radius of rotation at middle of box $=20 \mathrm{~cm}$.

$\theta=96^{\circ}$.

Total period $(t+T)=\mathrm{I}$ hour.

$\frac{t}{T}=3 \cdot \mathrm{I} 2$.

$R=3 \cdot 6 \mathrm{r}$.

All the radicles bent up.

$\therefore$ Point of equilibrium is below the lower edge of the box.

$\therefore r<\mathrm{I} 6 \mathrm{~cm}$.

$\therefore$ Cent. force $<8 \cdot 4$ I $\mathrm{mg}$.

$C<8.46 \mathrm{mg}$.

Thus $\frac{t}{T}=3 \cdot 12, \frac{C}{m g}<84 \cdot 6$.

$\therefore \frac{C T}{m g \cdot t}<2 \cdot 7 \mathrm{I}$.

Experiment 20. April 6, igir. I I a.m. to 8.30 p.m.

Radius of rotation at middle of box $=30 \mathrm{~cm}$.

$\theta=100^{\circ}$.

Total period $(t+T)=\mathrm{I}$ hour.

$\frac{t}{T}=7 \cdot 14$.

$R=3 \cdot 4$ I.

Point of equilibrium is about $2 \mathrm{~cm}$. below middle of box.

$\therefore r=28 \mathrm{~cm}$.

$C=\mathbf{I} 3 \cdot 1 \mathrm{mg}$.

Thus $\frac{t}{T}=7 \cdot 14, \frac{C}{m g}=13 \cdot 1$.

$\therefore \frac{C T}{m g \cdot t}=\mathbf{r} \cdot 83$.

EXPERIMeNT 21 . Oct. I9, I 9 I I. I2.30 p.m. to I0.30 p.m.

Radius of rotation at middle of box $=30 \mathrm{~cm}$.

$\theta=94^{\circ}$.

Total period $(t+T)=40 \mathrm{~m} .30 \mathrm{~s}$.

$\frac{t}{T}=5.04$.

$R=3.57$. 
Point of equilibrium is about $\mathbf{I} \mathrm{cm}$. below middle.

$\therefore r=29 \mathrm{~cm}$.

$C=\mathrm{I} 4.9 \mathrm{mg}$.

Thus $\frac{t}{T}=5.04, \frac{C}{m g}=14.9$.

$\therefore \frac{C T}{m g \cdot t}=2 \cdot 96$.

Experiment 22. April 3, I 9 I I. IO a.m. to 7.30 p.m.

Temp. $=25^{\circ} \mathrm{C}$.

Radius of rotation at middle of box $=30 \mathrm{~cm}$.

$\theta=94^{\circ}$.

Total period $(t+T)=20 \mathrm{~m}$.

$\frac{t}{T}=8 \cdot 92$.

$R=3 \cdot 3^{6}$.

Point of equilibrium is about $3 \mathrm{~cm}$. above middle of box.

$\therefore r=33 \mathrm{~cm}$.

$C=\mathrm{I} 5.0 \mathrm{mg}$.

$\frac{t}{T}=8 \cdot 92, \frac{C}{m g}=15.0$.

$\therefore \frac{C T}{m g \cdot t}=\mathrm{I} \cdot 68$.

Experiment 23. April 5, I9II. I 2 noon to 6.40 p.m.

Radius of rotation at middle of box $=30 \mathrm{~cm}$.

$\theta=100^{\circ}$.

Total period $(t+T)=\mathrm{I}$ hour.

$\frac{t}{T}=8 \cdot 84$.

$R=3 \cdot 44$.

All the radicles bent down.

$\therefore r>34 \mathrm{~cm}$.

$\therefore C>16.19 \mathrm{mg}$.

Thus $\frac{t}{T}=8.84, \frac{C}{m g}>16 \cdot 19$.

$\therefore \frac{C T}{m g \cdot t}>\mathrm{I} \cdot 83$.

Experiment 24. May 8, i9 i 1 . 9.30 a.m. to 7.30 p.m.

Temp. $=25^{\circ} \mathrm{C}$.

Radius of rotation at middle of box $=30 \mathrm{~cm}$.

$\theta=94^{\circ}$. 
Total period $(t+T)=\mathrm{I}$ hour.

$\frac{t}{T}=3 \cdot \mathrm{I} 6$.

$R=3.66$.

Point of equilibrium is about the middle of the box.

$\therefore r=30 \mathrm{~cm}$.

$C=16.22 \mathrm{mg}$.

Thus $\frac{t}{T}=3 \cdot 16, \frac{C}{m g}=\mathbf{1} 6 \cdot 22$.

$\therefore \frac{C T}{m g \cdot t}=$ about $5 \cdot \mathrm{I} 3$.

Experiment 25. April 29, I9I I. 9.30 a.m. to 6 p.m.

Temp. $=24^{\circ} \mathrm{C}$.

Radius of rotation at middle of box $=30 \mathrm{~cm}$.

$\theta=94^{\circ}$.

Total period $(t+T)=\mathbf{I}$ hour.

$\frac{t}{T}=6.00$.

$R=3.5$.

All radicles bent down.

$\therefore r>34 \mathrm{~cm}$.

$C>\mathrm{I} 6.8 \mathrm{mg}$.

Thus $\frac{t}{T}=6.00, \frac{C}{m g}>16.8$.

$\therefore \frac{C T}{m g \cdot t}>2 \cdot 8$.

EXPERIMENT 26. Oct. 2 I, I9 I I , 6.30 p.m. to Oct. 22, 10.30 a.m.

Radius of rotation at middle of box $=30 \mathrm{~cm}$.

$\theta=94^{\circ}$.

Total period $(t+T)=4 \mathrm{I} \mathrm{m}$.

$\frac{t}{T}=6 \cdot \mathrm{II}$.

$R=3.77$.

Point of equilibrium near middle of box.

$\therefore r=30 \mathrm{~cm}$.

$C=\mathrm{I} 7 \cdot 2 \mathrm{mg}$.

Thus $\frac{t}{T}=6 \cdot 11, \frac{C}{m g}=17 \cdot 2$.

$\therefore \frac{C T}{m g . t}=$ about $2 \cdot 82$. 
Experiment 27. Oct. I8, igi i. 9.20 a.m. to 6.30 p.m.

Radius of rotation at middle of box $=30 \mathrm{~cm}$.

$\theta=94^{\circ}$.

Total period $(t+T)=40 \mathrm{~m} \cdot 30 \mathrm{~s}$.

$\frac{t}{T}=9 \cdot 05$.

$R=3 \cdot 55$.

All radicles bent down (except two which grew irregularly).

$\therefore r>34 \mathrm{~cm}$.

$C>\mathrm{I} 7 \cdot 2 \mathrm{mg}$.

Thus $\frac{t}{T}=9 \cdot 05, \frac{C}{m g}>\mathrm{I} 7 \cdot 2$.

$\therefore \frac{C T}{m g \cdot t}>\mathbf{I} \cdot 90$

Experiment 28. April 7 , I9I I. I I a.m. to $6.3^{\circ}$ p.m.

Temp. $=24^{\circ} \mathrm{C}$.

Radius of rotation at middle of box $=30 \mathrm{~cm}$.

$\theta=94^{\circ}$.

Total period $(t+T)=\mathrm{I}$ hour.

$\frac{t}{T}=7 \cdot 07$.

$R=3 \cdot 5^{8}$.

All the radicles bent down.

$\therefore r>34 \mathrm{~cm}$.

$C>17.54 \mathrm{mg}$.

Thus $\frac{t}{T}=7.07, \frac{C}{m g}>17.54$.

$\therefore \frac{C T}{m g \cdot t}>2 \cdot 48$.

Experiment 29. Oct. 2, I 9 I I , I0.30 a.m., to Oct. 3, I0.5 a.m.

Radius of rotation at middle of box $=30 \mathrm{~cm}$.

$\theta=94^{\circ}$.

Total period $(t+T)=40 \mathrm{~m} .30 \mathrm{~s}$.

$\frac{t}{T}=\mathrm{II} \cdot \mathrm{II}$ 。

$R=3 \cdot 70$.

Point of equilibrium is near the top of the box (rather doubtful).

$\therefore r=$ about $34 \mathrm{~cm}$. (?).

$\therefore C=$ about $18.8 \mathrm{mg}$. (?).

Thus $\frac{t}{T}=$ II.II, $\frac{C}{m g}=$ about 18.8 ?

$\therefore \frac{C T}{m g \cdot t}=$ about $\mathrm{I} \cdot 7($ ?) 
These results are summed up in the following table :

\section{TABLE II.}

Helianthus annuus radicles. Temp. $=20^{\circ}-25^{\circ} \mathrm{C}$.

Results with long total periods (i. e. $20 \mathrm{~m}$. and upwards).

\begin{tabular}{|c|c|c|c|c|c|c|}
\hline \multirow{3}{*}{$\begin{array}{l}\text { No. of } \\
\text { Exp. }\end{array}$} & \multirow{3}{*}{$\frac{C}{m g}$} & \multirow{3}{*}{$\frac{t}{T}$} & \multirow{2}{*}{\multicolumn{3}{|c|}{$(t+T)$}} & $C T$ \\
\hline & & & & & & $\overline{m g \cdot t}$ \\
\hline & & & & $\mathrm{m}$. & S. & \\
\hline I9 & $<8.4^{6}$ & $3 \cdot 12$ & I & 0 & 0 & $<2.7$ I \\
\hline 20 & I $3 \cdot$ I & $7 \cdot 14$ & I & 0 & 0 & $I \cdot 83$ \\
\hline $2 \mathrm{I}$ & 14.9 & $5 \cdot 04$ & & 40 & 30 & $2 \cdot 96$ \\
\hline 22 & I $5 \cdot 0$ & $8 \cdot 9^{2}$ & & 20 & 0 & $I \cdot 68$ \\
\hline 23 & $>16.19$ & $8 \cdot 84$ & I & 0 & 0 & $>\mathbf{I} \cdot 83$ \\
\hline 24 & $16 \cdot 22$ & $3 \cdot 16$ & I & 0 & ० & $5 \cdot 13$ \\
\hline 25 & $>16.8$ & $6 \cdot 0$ & I & 0 & 0 & $>2.8$ \\
\hline 26 & $17 \cdot 2$ & $6 \cdot$ I I & & $4 I$ & 0 & $2 \cdot 82$ \\
\hline 27 & $>17 \cdot 2$ & $9 \cdot 05$ & & 40 & 30 & $>I \cdot 90$ \\
\hline 28 & $>$ I 7.54 & 7.07 & I & ० & 0 & $>2 \cdot 48$ \\
\hline 29 & 18.8 & (?) II I I I & & 40 & 30 & $>1 \cdot 7$ (? \\
\hline
\end{tabular}

By comparing the results in Tables I and II it will be seen that though the equation holds good when the total period is less than I $6 \mathrm{~min}$., yet $C T>m g$. $t$. when the total period is greater than $19 \mathrm{~min}$. This discrepancy was the cause of much confusion in the interpretation of earlier results. It is not easy to understand why, though a radicle grows straight under the influence of alternating stimuli of $10 \mathrm{mg}$. for I min. and I $\mathrm{mg}$. for Io min. in opposite directions, it does not grow straight under alternating and opposite stimuli of $10 \mathrm{mg}$. for $3 \mathrm{~min}$. and $\mathrm{I} \mathrm{mg}$. for $30 \mathrm{~min}$. ; yet such is undoubtedly the case. It was thought that some light might be thrown on these results if it were found that the presentation time for Helianthus radicles was more than $16 \mathrm{~min}$. and less than $20 \mathrm{~min}$., as in that case a critical time would be passed in the later experiments. But experiments were carried out to determine the presentation time of Sunflower radicles, and these show that this time is less than five minutes.

\section{Presentation Time for Radicles of Helianthus ainnus.}

This value was determined in the following way. Seedlings were grown in a pan of damp sand in the experimenting room which was kept at a temperature of 18 to $20^{\circ} \mathrm{C}$. They thus remained at the same temperature from the beginning of germination till the end of the experiment. When the radicles were 5 to $5 \mathrm{~mm}$. long, the seedlings were taken out, carefully washed in water at the temperature of the room, and pinned to squared corks covered with wet blotting-paper. The corks were pushed on to the 
long axis of a Pfeffer's clinostat and covered by a glass cylinder as shown in Pfeffer's 'Physiology of Plants', vol. iii, p. I69. Up to this time the seedlings were constantly held with radicles vertical. The axis was then attached to the clinostat. They were allowed to remain motionless during the exposition time, after which they were made to rotate at a rate of about one revolution in $2 \mathrm{~min}$. The following results were obtained :

\begin{tabular}{|c|c|c|c|c|c|c|c|c|c|c|}
\hline \multicolumn{2}{|c|}{$\begin{array}{c}\text { Exposition } \\
\text { time. }\end{array}$} & Temp. & $\begin{array}{l}\text { No. of } \\
\text { seedlings. }\end{array}$ & \multicolumn{6}{|c|}{ No. of radicles bent after } & $\begin{array}{c}\text { Percentage } \\
\text { bent. }\end{array}$ \\
\hline $\begin{array}{l}\text { Min. } \\
\text { Io }\end{array}$ & $\begin{array}{c}\text { Sec. }_{0} \\
0\end{array}$ & $20^{\circ} \mathrm{C}$. & 8 & - & 5 & - & 6 & 6 & - & $75 \%$ \\
\hline 8 & 0 & $\mathrm{I} 8^{\circ} \mathrm{C}$. & 9 & - & 5 & 5 & - & - & 8 & $89 \%$ \\
\hline 6 & 0 & $20^{\circ} \mathrm{C}$. & 8 & - & 4 & - & 5 & 5 & - & $63 \%$ \\
\hline 5 & o & $18^{\circ} \mathrm{C}$. & 9 & 4 & - & 5 & - & - & 5 & $55 \%$ \\
\hline 4 & 30 & $18^{\circ} \mathrm{C}$. & 16 & & 2 & - & 6 & - & 8 & $50 \%$ \\
\hline 3 & 0 & $20^{\circ} \mathrm{C}$. & 8 & - & 3 & - & 4 & 4 & - & $50 \%$ \\
\hline
\end{tabular}

Thus the presentation time is about 3 to $4 \frac{1}{2} \min$. at $18^{\circ}$ to $20^{\circ} \mathrm{C}$. Also Pekelharing ('09) showed that under stimulation greater than gravity the presentation time is inversely proportional to the stimulus; so if, in the experiments summarized in Table $I, t$ is greater than the presentation time for gravity, $T$ will also be greater than the presentation time for the centrifugal force.

We thus see that radicles may be exposed alternately to centrifugal forces and gravity for much longer periods than the presentation time in each direction, and yet show neutrality when $C T=m g . t$. We have therefore to look for some other explanation to account for the discrepancy in the results with still longer exposition periods.

The most probable solution to the difficulty is suggested by the work of Jost and Stoppel ('12). These authors showed that under the action of high centrifugal forces, though roots at first respond positively, they will after a lengthened period of stimulation respond negatively. He found that Lupin roots, under the influence of a centrifugal force of $29 \mathrm{mg}$., will usually bend outwards (i. e. positively), but some show a tendency to bend inwards after prolonged stimulation. With a centrifugal force of $42 \mathrm{mg}$. roots sometimes respond negatively after six hours' stimulation. With a centrifugal force of $70 \mathrm{mg}$. most roots bend inwards after two hours.

These results have a very important bearing on the present work. Roots at first respond to a high centrifugal force positively, but after a while when the stimulation is continued they gradually become less active in their response and may end by bending towards the centre of rotation. Now we may suppose that in my earlier experiments the radicles were not stimulated continuously for sufficient time by the centrifugal force to cause any tendency to negative response. But in the experiments summarized in Table II stimulation proceeded long enough to allow of a diminution in the activity of response, so that less time 
was required with normal gravitational stimulus in the opposite direction in order to counteract the tendency to bend outwards.

This result may be expressed as follows : When acted upon by a high centrifugal force roots at first perceive the stimulus fully, and the tendency to respond is proportional to the stimulating force. But after stimulation has proceeded for a certain time the tendency to respond falls off, and subsequent minutes are much less effective in their stimulating power. The actual period of stimulation by the centrifugal force (i.e. T) in Experi. ments Io to 18 is always less than I min.; in all the experiments summed up in Table II, $T$ is more than 2 min. Comparing Experiment $I_{3}$ (in which $T=38 \mathrm{sec}$.) with Experiment 22 (in which $T=121 \mathrm{sec}$.) it will be seen that the radicle tends to respond proportionally to the stimulus when it lasts for $3^{8} \mathrm{sec}$, , but not when it lasts for I2I sec. Thus the failure to respond fully begins before the expiration of two minutes.

\section{Experiments with Cucurbita Pepo.}

A few experiments were also done with the Marrow; and the following results were obtained. The seeds were first soaked in water in a dish placed on the hotwater pipes for a day and were then transferred to a pan containing sand. They need a high temperature $\left(20^{\circ}-30^{\circ} \mathrm{C}\right.$.) to germinate, and are usually ready for experimentation three days from the commencement of soaking.

Experiment I. Dec. IO, I 9 I 2. 10.5 a.m. to 3.40 p.m.

Radius of rotation at middle of box $=7 \mathrm{~cm}$.

$\theta=110^{\circ}$.

Total period $(t+T)=7 \mathrm{~m} .43 \mathrm{~s}$.

$\frac{t}{T}=3 \cdot 8$.

$R=3.93$.

Point of equilibrium is $\mathbf{I} \cdot 5 \mathrm{~cm}$. below middle of box.

$\therefore r=5.5 \mathrm{~cm}$.

Cent. force $=3.42 \mathrm{mg}$.

$\therefore C=3.42 \cos 20^{\circ}+\sin 20^{\circ}=3.5^{6} \mathrm{mg}$.

$\therefore \frac{C T}{m g \cdot t}=0.94$.

Experiment 2. Dec. I 2, I91 2. 2.10 p.m. to I0.45 p.m.

Radius of rotation at middle of box $=\mathbf{I} \mathbf{~ c m}$.

$\theta=102^{\circ}$.

Total period $(t+T)=5 \mathrm{~m}$.

$\frac{t}{T}=5 \cdot 64$.

$R=3.93$.

Point of equilibrium is $2.5 \mathrm{~cm}$. below middle of box.

$\therefore r=8.5 \mathrm{~cm}$. 
$\therefore$ Cent. force $=5.28 \mathrm{mg}$.

$C=5.28 \cos 12^{\circ}+\sin 12^{\circ}=5.37 \mathrm{mg}$.

$\therefore \frac{C T}{m g \cdot t}=0.96$.

Experiment 3. Dec. I 5, I 9 I 2. I 0.45 a.m. to 7.0 p.m.

Radius of rotation at middle of box $=20 \mathrm{~cm}$.

$\theta=95^{\circ}$.

Total period $(t+T)=\mathbf{I} \mathbf{~ m}$.

$\frac{t}{T}=\mathrm{I} \cdot 5 \cdot$

$R=3 \cdot 86$.

Point of equilibrium is at middle of box.

$\therefore r=20$.

$C=\mathrm{I} 2 \cdot 0$.

M.E.C. $=0.94$.

$\therefore C$ (corrected $)=\mathbf{I} \mathbf{I} \cdot 28$.

$\therefore \frac{C T}{m g . t}=0.98$.

Experiment 4. Dec. I6, I 9 I 2. IO. I 5 a.m. to 5.40 p.m.

Radius of rotation at middle of box $=25 \mathrm{~cm}$.

$\theta=96^{\circ}$.

Total period $(t+T)=\mathbf{I} \mathbf{~ m}$.

$\frac{t}{T}=\mathrm{I} 2 \cdot 8$.

$R=3 \cdot 83$.

Point of equilibrium is $2.5 \mathrm{~cm}$. below middle of box.

$\therefore r=22.5 \mathrm{~cm}$.

$C=\mathrm{I} 3.3 \mathrm{mg}$.

M.E.C. $=0.94$.

$\therefore C$ (corrected) $=\mathbf{1} 2 \cdot 5$.

$\therefore \frac{C T}{m g \cdot t}=0.98$.

Experiment 5. Dec. I6, igi i. 8.14 p.m. to Dec. I7, ir.io a.m.

Radius of rotation at middle of box $=30 \mathrm{~cm}$.

$\theta=94^{\circ}$.

Total period $(t+T)=5 \mathrm{~m} .30 \mathrm{~s}$.

$\frac{t}{T}=\mathrm{r} 3 \cdot 4$.

$R=3 \cdot 40$.

Point of equilibrium is at middle of box.

$\therefore r=30 \mathrm{~cm}$.

$C=14.0 \mathrm{mg}$.

$\therefore \frac{C T}{m g \cdot t}=\mathrm{I} \cdot 04$.

Note. This experiment was performed before the M.E.C. was adopted. 
Experiment 6. Dec. I6, I9I 2. 5.44 p.m. to I0.5 p.m.

Radius of rotation at middle of box $=25 \mathrm{~cm}$.

$\theta=95^{\circ}$.

Total period $(t+T)=\mathbf{I} \mathrm{m}$.

$\frac{t}{T}={ }_{5} \cdot 6$.

$R=3.97$.

Point of equilibrium is at middle of box.

$\therefore r=25 \mathrm{~cm}$.

$C=15.9 \mathrm{mg}$.

M.E.C. $=0.94$.

$C$ (corrected) $=\mathrm{I} 4.9 \mathrm{mg}$.

$\therefore \frac{C T}{m g . t}=0.96$.

TABLE III.

Cucurbita Pepo radicles. Temp. about $20^{\circ} \mathrm{C}$.

\begin{tabular}{|c|c|c|c|c|c|}
\hline $\begin{array}{c}\text { No. of } \\
\text { Exp. }\end{array}$ & $\frac{C}{m g}$ & $\frac{t}{T}$ & & $T)$ & $\frac{C T}{m g \cdot t}$ \\
\hline & & & $\mathrm{m}$. & S. & \\
\hline I & $3 \cdot 5^{6}$ & $3 \cdot 8$ & 7 & 43 & 0.94 \\
\hline 2 & $5 \cdot 37$ & $5 \cdot 64$ & 5 & 0 & 0.9 \\
\hline 3 & I I $\cdot 28$ & I I 5 & I I & 0 & 0.9 \\
\hline 4 & 12.5 & I $2 \cdot 8$ & I I & 0 & 0.98 \\
\hline 5 & I 4.0 & I 3.4 & 5 & $3^{\circ}$ & $I \cdot O$ \\
\hline 6 & I 4.9 & I $5^{\circ} 6$ & I I & 0 & 0.9 \\
\hline
\end{tabular}

\section{CONCLUSIONS.}

To obtain a clear idea of the place of the results obtained from this research in the science of geotropism, it is necessary to compare them with the results of other investigators in the same subject. Unfortunately, owing to the indefiniteness of our knowledge to-day, this is not easy to do. When Czapek ('98), Bach ('07), Pekelharing ('09), Ruitgers ('10), and others had given us a definite conception of presentation time and reaction time, with sufficient data on which to base theories of graviperception, another school, represented by Polowzow ('09), Arisz ('11), and Tröndle ('13) makes us sceptical about all previous work on this subject by maintaining that presentation time and reaction time are artificial concepts founded on the fallibility of our unaided vision. They hold that whilst presentation time may be regarded as the least time of exposure to a geotropic stimulus which will cause a response visible to the naked eye, and reaction time as the period which elapses from the first exposure to stimulus to the time when response becomes visible to the naked eye, yet, as a matter of fact, response 
occurs almost immediately after stimulation, though the movement can at first only be seen by the aid of a microscope.

Pekelharing ('10) subsequently remarks that the amount of bending which becomes visible to the naked eye is 'ein fester Punkt in dem Krümmungsprozess, der als Indikator einer bestimmten Reaktion benutzt werden kann'. Using the term 'presentation time' in this sense, we should expect marked inconsistencies in the results of different investigators. Also the naked eye test is scarcely as refined a test as might be desired, and results will involve the personal equation of the researcher as well as the individual peculiarities of the plants.

Some further compromise between the two points of view is possible. For it is noticeable that the latter list of authors always employed plantmembers in which the perceptive region was also capable of response, e. g. hypocotyls of Helianthus and coleoptiles of Avena. Now in Avena response occurs first near the apex of the coleoptile, and gradually successive basal zones become involved in the bending. Thus the reaction time is different for different parts of the coleoptile and hypocotyl; and Tröndle finds that the reaction time for any particular zone is proportional to its distance from the apex of the coleoptile, so that at the apex the reaction time will be theoretically zero. Now in roots the responding portion is not also sensitive, at any rate to gravity, though Newcombe ('09) and Jost ('12) have shown that it is sensitive to more powerful stimuli, such as prolonged centrifugal forces. Thus for radicles reaction time would appear to be necessarily a definite period; and presentation time would be the least period of stimulation, the effects of which do not die out before the expiration of the reaction time.

It is true that Czapek, Bach, Pekelharing, and Ruitgers also worked considerably with members in which the sensitive portion was also capable of response, and what value can be attached to their results will no doubt be ascertained by further researches of these investigators. Since, however, this paper is only concerned with radicles, it is unnecessary to deal generally with the subject of presentation time.

In determining the presentation time for radicles of Helianthus (see above, p. 746) it was found that in each experiment some radicles responded markedly, bending at right angles or beyond, while others did not bend at all. The presentation time was reckoned as that exposure which caused a noticeable bend in half the roots experimented on.

Thus the individual differences between different roots present another source of difficulty. It was found that some roots responded to the exposure of $3 \mathrm{~min}$., whilst others showed no inclination to bend after an exposure of $10 \mathrm{~min}$. One differs from another in delicacy of response as much as an expert athlete differs from the slowest 'hobbledehoy'. Yet reaction and presentation times have been worked out for different angles 
of inclination, different temperatures, \&c., by taking a dozen or so seedlings for each experiment, with the trust that differences between individuals will neutralize out when an average is taken. Tables of results can of course be made out from these experiments, and graphs drawn, but it shows a trustfulness amounting to credulity when a mathematically-minded investigator seriously deduces from such a graph that Reaction time $=\frac{\text { Constant }}{\sqrt{\sin a}}$, where $a$ is the angle of inclination to the vertical at which the plant-member is placed. ${ }^{1}$

But fortunately there is another method of work by which this difficulty of the individual differences can be overcome. This is to expose one and the same seedling alternately to two opposing stimuli so as to let the effects of the opposing stimuli neutralize each other in the plant. The relative values of the two stimuli can then be reckoned from the relative times during which they have acted. The principle of this method was employed by Newcombe ('05), Fitting ('05), Haynes ('05), and later by Maillefer ('09).

By means of his intermittent clinostat, Fitting showed that a hypocotyl exposed to the stimulus of gravity, alternately horizontal for a time $t$, and at an angle $\theta$ to the horizontal for a time $t^{\prime}$ remained straight when $\frac{t}{t^{\prime}}=\cos \theta$. Now if the letters $s+s^{\prime}$ be made to stand for the gravitational stimulus acting at right angles to the hypocotyl in the two positions, then $\frac{s^{\prime}}{s}=\cos \theta$. Thus $\frac{s^{\prime}}{s}=\frac{t}{t^{\prime}}$ or $s . t=s^{\prime} t^{\prime}$, when the times are so arranged that the stimuli produce a state of equilibrium in the plant.

Now though Fitting saw this relationship quite clearly, he did not insist on it, in view of the fact that the result might be read in other ways. Thus suppose $\theta=45^{\circ}$; on any theory of graviperception the effect of a stimulus acting at $45^{\circ}$ to the long axis of the hypocotyl must be different from the stimulus acting at right angles to it, and the difference between the two stimuli is not only quantitative, but also qualitative. ${ }^{2}$

Maillefer ('09) applied the principle of alternation of opposing stimulations to centrifugal forces, and within rather narrow limits obtained results similar to those shown in this paper. ${ }^{3}$ He did not deal with centrifugal forces higher than $2.07 \mathrm{I} \mathrm{mg}$. and he used a centrifugal wheel which rotated

1 Maillefer ('09).

2 'Aus der Tatsache, dass die geotropischen Erregungen sich annähernd verhalten wie die Sinus der Ablenkungswinkel, darf man nicht den Schluss ziehen, dass nur die auf der Längsachse des Sprosses rechtwinklige Komponente für die Krümmung in Betracht kommt. Diese Tatsache dürfte vielmehr nur aus den Beziehungen zwischen den Reizzuständen, die in verschiedenen Ablenkungswinkeln geschaffen werden, erklärt werden können. Manches spricht dafür, dass diese Reizzustände nicht nur quantitativ, sondern auch qualitativ verschieden sind.'-Fitting ('05), p. 395.

3 I did not know of Maillefer's paper till all my results had been obtained, 
in the vertical plane. Such an instrument is open to the serious objection that the plant-members are not subjected to a constant centrifugal force. For at the bottom of each rotation gravity works with the centrifugal force (giving resultant $C+m g$ ); at the top of each rotation gravity works in opposition to the centrifugal force (giving resultant $C-m g$ ); whilst in intervening positions gravity and the centrifugal force work at an angle to each other producing a resultant which is not directed along a radius of the circle of rotation. Thus when $C$ is less than $m g$, the resultant force at the top of a rotation acts towards the centre of the wheel.

Pekelharing ('10, pp. 290,303) has shown that the presentation time for centrifugal forces is the same whether the seedlings be placed on a centrifuge with horizontal or vertical axis. But Maillefer has not really proved that ' pour que l'induction géotropique produite par une force $f_{1}$ soit égale à l'induction produite par une force $f_{2}$, il faut que le rapport $\frac{f_{1}}{f_{2}}$ soit égal au rapport $\frac{t_{2}}{t_{1}}$ des temps pendant lesquels les forces agissent', because his forces $f_{1}$ and $f_{2}$ were not constant, but vary with each position in each revolution. Also when $f_{1}$ or $f_{2}$ is less than $m g$ in his experiments, then since $f-m g$ will be negative, the force is really a mixture of positive and negative forces.

In the experiments described in this paper the radicles were subjected to alternating forces which always acted at right angles to the radicles and in opposite directions to each other. One of the alternating forces was always gravity and the other was a centrifugal force between $3 \mathrm{mg}$. and and $2 \mathrm{I} \mathrm{mg}$. The results obtained show definitely that if gravity acts for time $t$ and the centrifugal force for time $T$, then the radicles remain straight so long as $\frac{C}{m g}=\frac{t}{T}$, or $C T=m g . t$. Or, expressing this generally, if $s$ and $s^{\prime}$ are two stimulating forces acting at right angles to the radicles for alternating periods of $t$ and $t^{\prime}$, then when equilibrium is maintained $s . t=s^{\prime} t^{\prime}$, i. e. the amount of stimulus in $m g$. seconds is the same in each direction (cf. Maillefer, '09, and Pekelharing, '10). ${ }^{1}$.

Since, in the present chaotic state of the science of geotropism, we do

1 Pekelharing states the law as follows:- 'Das Produkt von wirkender Kraft und Reizzeit ist konstant.' She notes that this 'Produktregel' has been proved for four cases :-(I) Fitting: Intermittent stimulation at different angles of inclination ; (2) Pekelharing: Presentation time at different angles; (3) Maillefer : Intermittent stimulation with different centrifugal forces; (4) Pekelharing: Presentation time with different centrifugal forces. 
not even know whether presentation time and reaction time have any objective meaning, it came as rather a relief to find that in the experiments recorded in this paper, we have to deal with periods which far exceed the presentation time, as determined in the usual way, for Helianthus radicles. Thus in most of the experiments recorded in Table I there can be no doubt that each interval of exposure to gravity or centrifugal force had been fully perceived by the radicles, and the machinery had been set going which would normally result in response alternately in the two directions. In this case one of two things must have happened ; either neutralization took place in the motor mechanism so that no movement actually became expressed, or movement may actually have occurred first in one direction and then in the other, and so on in alternation. It is the second of these alternatives, as will be seen below, which most satisfactorily corresponds to the facts.

Zielinski ('11) introduced the term 'kritische Zeit' to stand for the shortest period of stimulation, the response to which is not inhibited by an exactly similar equal-timed stimulation in the opposite direction following immediately after. To quote Zielinski's tables for the radicles of two plants:

\begin{tabular}{|c|c|c|c|c|}
\hline lep & $\begin{array}{c}\text { Temp. } \\
17^{\circ}-18^{\circ} \mathrm{C} .\end{array}$ & $\begin{array}{l}\text { Pres. Time. } \\
5.5 \text { min. }\end{array}$ & $\begin{array}{c}\text { Critical Time. } \\
6 \text { min. }\end{array}$ & $\begin{array}{c}\text { Reaction Time. } \\
25.5 \mathrm{~min} .\end{array}$ \\
\hline albu & $25^{\circ}-27^{\circ} \mathrm{C}$. & & 2, & $12.5 \%$ \\
\hline & $25^{\circ}-27^{\circ} \mathrm{C}$ & $\begin{array}{cc}8 \cdot 5 \\
2 & \prime \prime\end{array}$ & $\begin{array}{l}11 \text { ", } \\
7\end{array}$ & $\begin{array}{rl}40 \cdot 5 & ", \\
3 \cdot 3 & ",\end{array}$ \\
\hline
\end{tabular}

This means that if a radicle of Lepidium sativum be kept at a temperature of $17^{\circ}-18^{\circ} \mathrm{C}$. and be placed horizontally for $5^{\circ} 6 \mathrm{~min}$. and then be turned through $180^{\circ}$ and be kept horizontal again for $5.6 \mathrm{~min}$. no movement is noticeable. Whereas, if it be kept for $7 \mathrm{~min}$. in each position, a movement is noticeable first in one direction and then in the other.

The critical time for Helianthus has not been determined; but since the presentation time for the temperature at which my experiments were carried out is less than 5 min., the critical time is almost certainly less than Io min. Thus in cases such as Experiment 14, there can be no reasonable doubt that the radicles actually moved during the course of the experiment first in one direction and then in the other, and so on in alternation, and that the ultimate equilibrium was due to the neutralization of actual movements.

Now suppose for any such experiment the centrifugal force working for time $T$ and gravity working for time $t$ neutralize each other when alternated, then since movement has actually taken place in response to each single stimulus the amount of response that took place to $C$ acting for time $T$ must have been equal to the amount of response that took place to $m g$. acting for time $t$.

But the experiments described above have shown that under these circumstances $C T=m g . t$, and each of these quantities is of the form S.t 
where $S$ is the value of the stimulating force in terms of $m g$, and $t$ is the number of seconds during which it acts. Thus the conclusion is reached that in any given radicle a constant amount of response takes place to a stimulus of a given number of $\mathrm{mg}$. sec. units, however this number may be made up, so long as the time of exposure to the stimulus is not long.

This last reservation will be understood by reference to Tables I and II, from which it will be seen that for Helianthus radicles the statement is true so long as each single exposure to the stimulus of gravity does not exceed fifteen minutes, and the exposure to a centrifugal force is correspondingly small. The fact that the law does not hold good for longer induction periods becomes explicable, as shown above, from the discovery of Jost and Stoppel ('12) that roots respond negatively to prolonged stimulation by high centrifugal forces.

This result is in contradiction to Pekelharing's conclusions. She found that the geotropic response in coleoptiles displaced $\mathrm{I} 7 \mathrm{I}^{\circ}$ from the normal was less than that in coleoptiles displaced $5^{\circ}$ from the normal, though in the former position the stimulus acting at right angles to the coleoptiles was greater than in the latter. She continues: 'aus diesen Mitteilungen geht aber hervor, dass die alten Untersuchungen über die Reaktionskrümmungen nicht mehr zu gebrauchen sind, und meine Erfahrung warnt vor der Hypothese dass gleich grosse Reize auch gleich grosse Krïmmungen verursachen wiirden. Augenscheinlich hängen diese Krümmungen nicht nur von Reizintensität und Reizdauer, sondern auch noch von einem oder mehreren, uns bis jetzt unbekannten Faktoren ab.' (Italics are mine.)

The hypothesis, italicized in the above quotation, against which Pekelharing warns us, has, however, been proved to be true for the case of centrifugal forces by the results of the present research.

\section{SUMMARY.}

r. A comparison of the value of different degrees of centrifugal force as geotropic stimuli was obtained by the method of continued alternation of short-timed exposures to gravity and a centrifugal force in opposite directions. A machine was constructed to accomplish this alternation by which centrifugal forces up to $2 \mathrm{I} \mathrm{mg}$. could be obtained. The centrifugal ' wheel' rotated in the horizontal plane and was driven by an electric motor. A description of this machine is given in the text.

2. The seedlings were pinned to the back of a box, which automatically took up a nearly horizontal position when the 'wheel' was rotating. Thus the radicles on the outer side of the box were subjected to a higher centrifugal force than those towards the inner side. If the exposures to the centrifugal force were neutralized by the alternated opposing exposures to gravity at a certain point in the box, the radicles at this point would not 
bend. Those, however, which were further out in the box would bend outwards, and those further in would bend inwards. Thus a point of equilibrium could be determined with very fair accuracy, and the centrifugal force at this point of equilibrium could be deduced from the number of rotations made by the wheel in a known time and the radius of rotation of the point of equilibrium.

3. It was found that if a centrifugal force $C$, working for a time $T$, be regularly alternated with gravity $(m g$ :) working for a time $t$, then equilibrium is only established when $\frac{C T}{m g \cdot t}=\mathrm{I}$. (The actual value of $\frac{C T}{m g \cdot t}$ as deduced from the average of eighteen successful experiments with radicles of Helianthus annus was 0.99.)

This equation may be expressed thus: $C T=m g . t$, i. e. the product of the force into the time in each direction is the same. The average experimental value of $\frac{C T}{m g . t}$ for six experiments with radicles of Cucurbita Pepo was 0.97 .

4. The equation $\frac{C T}{m g \cdot t}=\mathrm{I}$ does not hold good if the individual periods of exposure to gravity and centrifugal force are long. When $(T+t)$ was as much as $20 \mathrm{~min}$. it was found that for the point of equilibrium $\frac{C T}{m g . t}>\mathrm{I}$; i. e. the centrifugal force had to be allowed to act for a longer time than would have been expected from previous experiments. This is probably connected with the fact, discovered by Jost and Stoppel, that radicles may respond negatively to prolonged exposure to centrifugal forces. Though, in the case of the present experiments, the period of exposure was not sufficiently long to cause a negative response, it may nevertheless have been sufficient to allow of a falling-off in the activity of the positive response.

5. The presentation time for Helianthus radicles was determined in the usual way, and was found to lie between 3 and $4 \frac{1}{2}$ min., at a temperature of I $8^{\circ}-20^{\circ} \mathrm{C}$.

On the intermittent centrifuge, single exposures to gravity might be much longer than this without any failure of the equation $\frac{C T}{m g . t}=\mathrm{I}$.

6. From theoretical considerations it is clear that, at any rate in many of the experiments, actual movement must have taken place in response both to gravity and to the centrifugal force; but as the movement was of equal extent in each direction, there was no resultant bending. From this fact it is deduced that a given small amount of stimulation, reckoned in mg. sec. units, produces the same amount of response in a given radicle, however the amount of stimulation may be made up. For instance, 
a stimulus of Io $\mathrm{mg}$. acting for I min. produces the same amount of response as a stimulus of I mg. acting for Io min. On the other hand, as stated in $\S 4$, it is found that a stimulus of $10 \mathrm{mg}$. acting for $3 \mathrm{~min}$. does not produce so great a bend as a stimulus of I $\mathrm{mg}$. acting for $30 \mathrm{~min}$.

In conclusion I desire to express my thanks to Professor S. H. Vines for his constant help and encouragement in the course of this work.

\section{LITERATURE CITED.}

Andrews, F. M. ('03) : Die Wirkung der Centrifugalkraft auf Pflanzen. Jahrb. f. wiss. Bot., xxxviii. I.

ARISZ, W. H. ('11) : On the Connection between Stimulus and Effect in Phototropic Curvatures of Seedlings of Avena sativa. Proc. of the Sect. of Sciences. Konink. Akad. Weten., vol. xiii, p. 1022 .

BACH, H. ('07) : Über die Abhängigkeit der geotropischen Präsentations- und Reaktionszeit von verschiedenen Aussenbedingungen. Jahrb. f. wiss. Bot., xliv. 57.

Blaauw, A. H., and Went, F. W. C. ('08): On the Investigation of Mr. A. H. Blaauw on the Relation between the intensity of Light and the Length of Illumination on the Phototropic Curvatures in Seedlings of Avena sativa. Proc. of the Sect. of Sciences. Konink. Akad. Weten., vol. xi, p. 230 .

Buder, J. ('08): Untersuchungen zur Statolithenhypothese. Ber. der Deut. Bồt. Ges., xxvi. (Festschrift), 162 .

CzAPEK, F. ('95): Untersuchungen über Geotropismus. Jahrb. f. wiss. Bot., xxvii. 243. ('98): Weitere Beiträge zur Kenntniss der geotropischen Reizbewegungen. Jahrb. f. wiss. Bot., xxxii. I 75 .

Elfving, L. ('80): Beitrag zur Kenntniss der Einwirk. d. Schwerkraft auf die Pflanzen. Sep.-Abdr. aus Acta Soc. Scient. Fennic., xii. 33.

FitTiNG, H. ('05) : Untersuchungen über den geotropischen Reizvorgang. Jahrb. f. wiss. Bot., xli. $22 \mathrm{I}$.

Giltay, E. ('10): Einige Betrachtungen und Versuche über Grundfragen beim Geotropismus der Wurzel. Zeitschr. f. Bot., ii. 305 .

Haberlandt, G. ('03): Zur Statolithentheorie des Geotropismus. Jahrb. f. wiss. Bot., xxxviii. 447 .

Haynes, J. A. ('05): The Angle of Deviation from the Normal Vertical Position at which Stems show the Strongest Geotropic Response. Amer. Naturalist, vol. xxxix, p. 77.

HeIlbronn, A. L. ('12): Über Plasmaströmungen und deren Beziehung zur Bewegung umlagerungsfähiger Stärke. Berichte d. Deut. Bot. Ges., xxx. J42.

Jost, L. ('12) : Die Verteilung der geotropischen Sensibilität in der Wurzelspitze. Zeitschr. f. Bot., iv. I6r.

Jost, L., and Stoppel, R. ('12): Die Veränderung der geotropischen Reaktion durch Schleuderkraft. Zeitschr. f. Bot., iv. 206.

Knight, T. A. (1806): (Selection from his Physiological and Horticultural Papers, I84I.) Paper VII : On the Direction of the Radicle and Germen during the Vegetation of Seeds.

Küster, E. ('04) : Beiträge zur Kenntniss der Wurzel- und Sprossbildung an Stecklingen. Jahrb. f. wiss. Bot., xl, 279 .

Maillefer, A. ('09): Étude sur le géotropisme. Bull. de la Soc. Vaudoise des Sc. Nat,, vol. xlv, p. 277.

('10): Étude sur la réaction géotropique. Bull. de la Soc. Vaudoise des Sc. Nat., vol. xlvi, p. 235 . 


\section{Hiley.-On Centrifugal Force as Geotropic Stimulus.}

Newcombe, F. C. ('05): Geotropic Response at various Angles of Inclination. Ann. Bot., vol. $x i x$, p. $3^{\mathrm{I}} \mathrm{I}$.

('09): Gravitation Sensitiveness not confined to Apex of Root. Beihefte z. Bot. Centralbl., xxiv. 96.

PÁ́L, ÁRPÁD ('11): Analyse des geotropischen Reizvorganges mittels Luftverdünnung. Jahrb. f. wiss. Bot., l. I.

Pekelharing, C. J. ('09): Investigations on the Relation between the Presentation Time and Intensity of Stimulus in Geotropic Curvatures. Proc. of the Sect. of Sciences. Konink. Akad. v. Weten., Amsterdam, vol. xii, p. 65.

Pekelharing, C. J. (Rutten) ('10): Untersuchungen über die Perzeption des Schwerkraftreizes. Recueil des Trav. Bot. Néerlandais, vol. vii, p. $24 \mathrm{I}$.

Pfeffer, W. ('97): Physiology of Plants. Eng. Ed. by A. J. Ewart, Clarendon Press.

Polowzow, W. ('09): Untersuchungen über Reizerscheinungen bei den Pflanzen. Jena.

Pringsheim, E. G. ('12): Die Reizbewegungen der Pflanzen. Berlin.

RüTgers, A. A. L. ('10): The Influence of Temperature on the Presentation time in Geotropism. - Proc. of the Sect. of Sciences. Konink. Akad. v. Weten., Amsterdam, vol. xii, p. 476.

SACHS, J. ('74) : Über das Wachstum der Haupt- und Nebenwurzeln. Arbeiten d. bot. Inst. in Würzb ur.5) .

Schwarz, Fr. ('81): Der Einfluss der Schwerkraft auf das Längenwachsthum der Pflanzen. Untersuch. a. d. Bot. Inst. zu Tübingen.

TröNDLE, A. ('13): Der zeitliche Verlauf der geotropischen Reaktion und die Verteilung der geotropischen Sensibilität in der Koleoptile. Jahrb. f. wiss. Bot., lii. I86.

Wigand, A. ('54): Bot. Untersuchungen. Braunschweig.

Zielinski, F.F. ('11) : Über die gegenseitige Abhängigkeit geotropischer Reizmomente. Zeitschr. f. Bot., iii. 


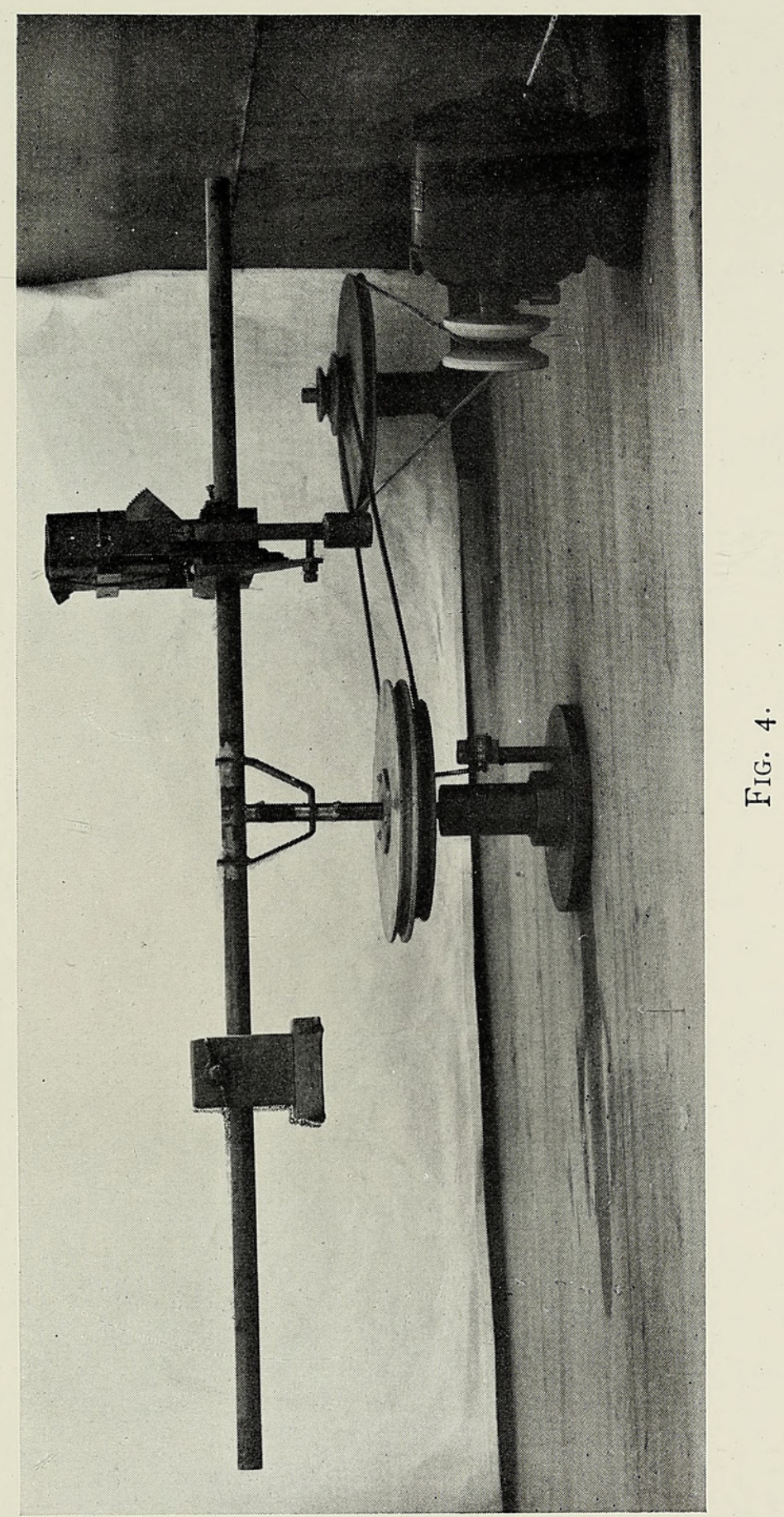



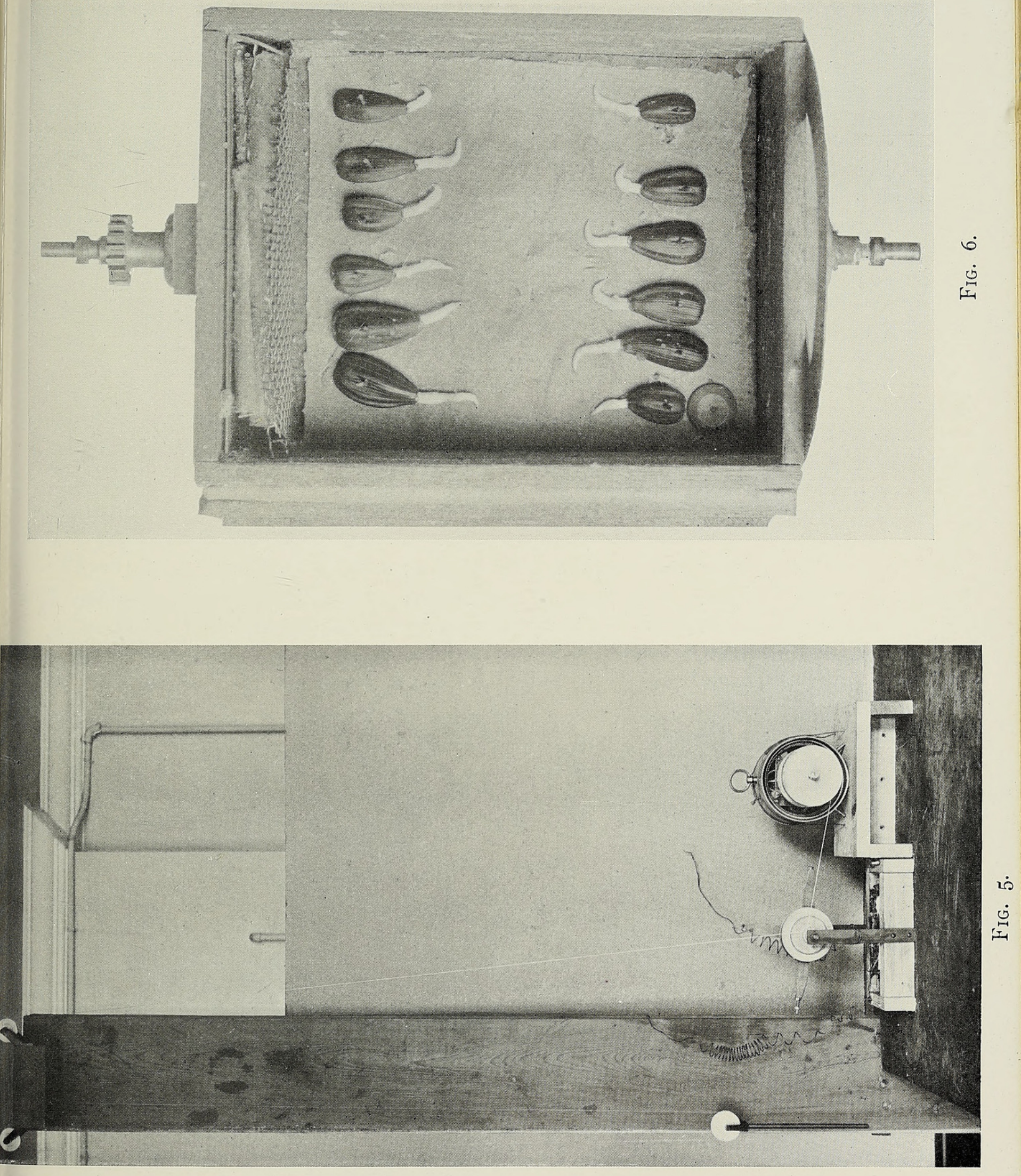

HILEY-CENTRIFUGAL FORCE 


\section{$2 \mathrm{BHL}$ Biodiversity Heritage Library}

Hiley, W. E. 1913. "On the value of different degrees of centrifugal force as geotropic stimuli." Annals of botany 27, 719-758. https://doi.org/10.1093/oxfordjournals.aob.a089485.

View This Item Online: https://www.biodiversitylibrary.org/item/237410

DOI: https://doi.org/10.1093/oxfordjournals.aob.a089485

Permalink: https://www.biodiversitylibrary.org/partpdf/319998

\section{Holding Institution}

Smithsonian Libraries

\section{Sponsored by}

Biodiversity Heritage Library

\section{Copyright \& Reuse}

Copyright Status: Not in copyright. The BHL knows of no copyright restrictions on this item.

This document was created from content at the Biodiversity Heritage Library, the world's largest open access digital library for biodiversity literature and archives. Visit BHL at https://www.biodiversitylibrary.org. 